\title{
Pan-Arctic linkages between snow accumulation and growing-season air temperature, soil moisture and vegetation
}

\author{
K. A. Luus ${ }^{1,2}$, Y. Gel ${ }^{3,4}$, J. C. Lin $^{5,1}$, R. E. J. Kelly ${ }^{2}$, and C. R. Duguay ${ }^{2}$ \\ ${ }^{1}$ Earth and Environmental Sciences, University of Waterloo, Waterloo, ON, Canada \\ ${ }^{2}$ Geography and Environmental Management, University of Waterloo, Waterloo, ON, Canada \\ ${ }^{3}$ Statistics and Actuarial Science, University of Waterloo, Waterloo, ON, Canada \\ ${ }^{4}$ Department of Mathematics and Mechanics, Saint Petersburg State University, Russia \\ ${ }^{5}$ Atmospheric Sciences, University of Utah, Salt Lake City, UT, USA
}

Correspondence to: K. A. Luus (kaluus@uwaterloo.ca)

Received: 20 December 2012 - Published in Biogeosciences Discuss.: 31 January 2013

Revised: 22 August 2013 - Accepted: 16 September 2013 - Published: 22 November 2013

\begin{abstract}
Arctic field studies have indicated that the air temperature, soil moisture and vegetation at a site influence the quantity of snow accumulated, and that snow accumulation can alter growing-season soil moisture and vegetation. Climate change is predicted to bring about warmer air temperatures, greater snow accumulation and northward movements of the shrub and tree lines. Understanding the responses of northern environments to changes in snow and growingseason land surface characteristics requires: (1) insights into the present-day linkages between snow and growing-season land surface characteristics; and (2) the ability to continue to monitor these associations over time across the vast panArctic. The objective of this study was therefore to examine the pan-Arctic (north of $60^{\circ} \mathrm{N}$ ) linkages between two temporally distinct data products created from AMSR-E satellite passive microwave observations: GlobSnow snow water equivalent (SWE), and NTSG growing-season AMSRE Land Parameters (air temperature, soil moisture and vegetation transmissivity). Due to the complex and interconnected nature of processes determining snow and growingseason land surface characteristics, these associations were analyzed using the modern nonparametric technique of alternating conditional expectations (ACE), as this approach does not impose a predefined analytic form. Findings indicate that regions with lower vegetation transmissivity (more biomass) at the start and end of the growing season tend to accumulate less snow at the start and end of the snow season, possibly due to interception and sublimation. Warmer air temperatures at the start and end of the growing season were
\end{abstract}

associated with diminished snow accumulation at the start and end of the snow season. High latitude sites with warmer mean annual growing-season temperatures tended to accumulate more snow, probably due to the greater availability of water vapor for snow season precipitation at warmer locations. Regions with drier soils preceding snow onset tended to accumulate greater quantities of snow, likely because drier soils freeze faster and more thoroughly than wetter soils. Understanding and continuing to monitor these linkages at the regional scale using the ACE approach can allow insights to be gained into the complex response of Arctic ecosystems to climate-driven shifts in air temperature, vegetation, soil moisture and snow accumulation.

\section{Introduction}

Interactions between cryospheric, biological and atmospheric components play an important role in the Arctic climate system (Serreze and Barry, 2005), and linkages between snow water equivalent (SWE), soil moisture, air temperature and the quantity of vegetation determine the carbon balance of northern regions (Sitch et al., 2007). Northern field studies have determined that snow accumulation is influenced by the snow season climate (Sturm et al., 1995). Snow accumulation is also known to be altered by vegetation species compositions. Patches of shrubs reduce windspeeds, leading to the deposition of windblown snow particles and an increase in snow accumulation immediately 
downwind (Sturm et al., 2001a). Regions with greater quantities of evergreen biomass tend to retain less snow due to interception and sublimation (Pomeroy et al., 2002). Changes in snow accumulation have also been found to alter vegetation species composition at an Arctic tundra site (Wahren et al., 2005), and have been found to result in anomalous soil moisture values over the following growing season in a semiarid area of Eurasia (Shinoda, 2001). Field-scale associations between snow and growing-season land surface characteristics are therefore relatively well understood.

However, due to the scale dependence of many processes, the spatial heterogeneity of Arctic regions, and the lack of exhaustive pan-Arctic coverage by ground-based sampling, understanding the complex response of pan-Arctic environments to climate change relies on the ability to characterize land surface properties using remote sensing observations, and to analyze shifts in the associations between snow and growing properties at the regional to circumpolar resolution. It is therefore important that these land surface characteristics and their seasonal linkages be well understood as they appear in both field and remote sensing observations.

Analyzing these linkages in remote sensing observations could also assist in improving model estimates of processes such as carbon cycling, which respond to snow accumulation as well as growing-season soil moisture, air temperature and vegetation (Walker et al., 1999; Sullivan et al., 2008; Morgner et al., 1998). Model estimates of these processes typically rely on remote sensing observations of growingseason land surface characteristics, but do not usually include snow season remote sensing observations (Luus et al., 2013b). Findings regarding the pan-Arctic associations between snow and growing-season land surface characteristics could therefore have important implications for future efforts to understand and model ecosystem processes and their responses to climate change.

The passive microwave data products analyzed in this study were created by a consortium of researchers led by the Finnish Meteorological Institute (FMI) (e.g. Luojus et al., 2009) and the University of Montana's Numerical Terradynamic Simulation Group (NTSG) (e.g. Jones and Kimball, 2012) from Advanced Microwave Scanning Radiometer for the Earth Observing System (AMSR-E) observations. The FMI-led research group produced GlobSnow SWE, and the NTSG group produced AMSR-E Land Parameter growingseason estimates of air temperature, soil moisture, vegetation transmissivity and fractional water content. A comprehensive summary of these data sets can be found in Appendix A.

The central aim of this study was to analyze linkages between GlobSnow SWE and NTSG AMSR-E Land Parameters air temperature, soil moisture and vegetation transmissivity for the entire terrestrial region north of $60^{\circ} \mathrm{N}$. The objectives were to examine:
- similarities in general tendencies of the land surface between seasons (e.g. do regions that have greater quantities of vegetation also tend to have more SWE?)

- whether regions that experience certain conditions at the end of the growing season tend to receive altered quantities of SWE (e.g. do areas that tend to be warmer at the end of the growing season tend to accumulate less snow in the early portion of the snow season?)

- associations between snow accumulation at the end of the snow season and land surface variables at the start of the growing season (e.g. do sites with slower snowmelt at the end of the snow season tend to have drier soil moisture at the start of the growing season?)

The modern nonparametric approach of Alternating Conditional Expectations (ACE) was applied to analyze the relationships between each pair of snow and growing-season variables from passive microwave observations. As the ACE technique has not yet been widely used in the biogeosciences, a thorough explanation of the theory behind ACE and the strategies used to assess ACE output are provided below.

\section{Alternating conditional expectations (ACE)}

The ACE approach can be used to describe the underlying, nonlinear relationships that exist between predictor and response variables (Breiman and Friedman, 1985; Frank and Lanteri, 1988). Previous work has indicated that the ACE technique can be used to reveal complex relationships that exist in large data sets (e.g. Gel, 2007).

A standard linear regression approach provides a least squares estimate of the linear relationship between a response variable $(y)$ and one or more predictor variables $\left(x_{j}\right)$ according to regression coefficients $\left(a_{j}\right)$ and an intercept $\left(a_{0}\right)$ :

$y=a_{0}+\sum_{j=1}^{p} a_{j} x_{j}$.

Techniques such as linear regression and principal component analysis (PCA) are based on the assumption that linear associations exist between response and predictor variables. However, in cases where this assumption is unfounded, applying a linear regression or PCA approach can lead to erroneous or misleading results, as described by Wang and Murphy (2004).

A nonlinear approach should therefore be applied whenever it is recognized that only a small portion of the variance in the response variable can be explained using a linear model. One common approach is to apply nonlinear transformations (e.g. polynomial, logarithmic, square root) to the response or predictor variables in order to linearize their association, and to then use the transformed output in a linear model. However, selecting the best possible transformation 
for a given data set can be challenging, especially over large or noisy data sets, and can be complicated by the fact that the optimal transformation may not be monotonic or of a standard analytic form.

The ACE technique uses an iterative method to find the least squares optimal smoothing functions $g$ and $f_{j}$ that linearize the association between $g(y)$ and $f_{j}\left(x_{j}\right)$ :

$g(y)=\sum_{j=1}^{p} f_{j}\left(x_{j}\right)$,

where the $g$ and $f_{j}$ functions need not be monotonic or of a standard analytic form. By analyzing the shape of the point pairs $\left[x_{j}, f_{j}\left(x_{j}\right)\right]$ and $[y, g(y)]$, insights can be gained into the underlying nonlinear relationships between $y$ and $x_{j}$ (Wang and Murphy, 2004; Breiman and Friedman, 1985; Frank and Lanteri, 1988).

The optimal smoothing functions $g$ and $f_{j}$ are identified by minimizing the error function

$\epsilon^{2}\left(g, f_{1}, \ldots f_{p}\right)=E\left[g(y)-\sum_{j}^{p} f_{j}\left(x_{j}\right)\right]^{2}$

through an iterative two-loop process for $p$ predictors. The ACE algorithm uses initial guesses $g^{0}(y)=\frac{y}{\sqrt{\left[E(y)^{2}\right]}}$ and $f_{j}^{0}\left(x_{j}\right)=b_{j} x_{j}, j=1, p$, where $b_{j}$ are coefficients estimated through ordinary least squares regression. A loop is then used to optimize the predictor transformation function $f_{j}^{k}$ where $k$ refers to the iteration:

$f_{j}^{k+1}\left(x_{j}\right)=E\left[g^{k}(y)-\sum_{i \neq j} f_{i}^{k}\left(x_{i}\right) \mid x_{j}\right]$.

Once $\epsilon^{2}$ fails to decrease, the values of $f_{j}\left(x_{j}\right)$ have been selected. The response transformation function $g(y)$ is then optimized in an outer loop using the final values of $f_{j}^{k}\left(x_{j}\right)$

$g^{k+1}(y)=\frac{E\left[\sum_{j} f_{j}^{k}\left(x_{j}\right) \mid y\right]}{\sqrt{E\left[E\left[\sum_{j} f_{j}^{k}\left(x_{j}\right) \mid y\right]\right]^{2}}}$

until $\epsilon^{2}$ again fails to decrease (Breiman and Friedman, 1985; Frank and Lanteri, 1988). Through this algorithm, the optimal transformations $f_{j}\left(x_{j}\right)$ and $g(y)$ are identified.

Proof exists that the ACE algorithm results in convergence of $f_{j}$ and $g$ to their optimal transformations, which need not be either of a specific analytic form or monotonic (Breiman and Friedman, 1985; Frank and Lanteri, 1988). The resulting output is therefore expressed according to the point pairs $\left[x_{j}, f_{j}\left(x_{j}\right)\right]$ and $[y, g(y)]$, rather than by a specific mathematical form. Visual analysis consists of examining scatter plots of these point pairs, where each plot indicates the original data values (e.g. $y$ and $x_{1}$ ) relative to their transformed values (e.g. $g(y)$ and $f_{1}\left(x_{1}\right)$ ) (Frank and Lanteri, 1988). Since the ACE technique finds the least squares optimal values of $g$ and $f_{j}$ such that the linear association between $g(y)$ and $\sum_{j=1}^{p} f_{j}\left(x_{j}\right)$ is maximized, it is crucial that the plots of point pairs $\left[x_{j}, f_{j}\left(x_{j}\right)\right]$ and $[y, g(y)]$ be interpreted relative to one another.

\subsection{ACE examples}

In order to demonstrate how the output from ACE is analyzed, three simple but detailed examples are provided. In Figs. 1 and 2, temporal associations are assessed between two meteorological variables measured at the University of Waterloo Weather Station in 2000. Example 1 focuses on the associations between soil temperature and air temperature, and example 2 describes the associations between barometric pressure and precipitation. The relationships between $x$ and $y$ can be easily detected without the ACE technique in Fig. 1 but not Fig. 2. In example 3, the first plot of the actual ACE results from this paper is interpreted very thoroughly (Fig. 4a) in order to provide a foundation for interpreting all ACE plots shown in this paper.

When both air temperature $(x)$ and soil temperature at $20 \mathrm{~cm}$ depth $(y)$ are plotted over time (Fig. 1 left), examination of these plots indicates that soil and air temperatures are greatest in summer, and that air temperature shows greater diurnal variation than soil temperature in winter. Plotting soil temperature against air temperature ( $x$ vs. $y$ ) indicates that an approximately linear association appears to exist between these variables at warm air temperatures $\left(\approx>-5^{\circ} \mathrm{C}\right)$. Similarly, point pair output from the ACE algorithm (Fig. 1 right) indicates an approximately positive linear association between soil temperature and transformed soil temperature $[y, g(y)]$, and an approximately logarithmic association between air temperature and transformed air temperature $[x$, $f(x)]$ when air temperature is $>-5^{\circ} \mathrm{C}$.

When analyzed together, the ACE point pair output indicates that a positive association exists between soil and air temperatures. The steepness of the slope in the plot of $[x$, $f(x)$ ] appears to diminish at air temperatures above $\approx 20^{\circ} \mathrm{C}$, and below $-5^{\circ} \mathrm{C}$. At subzero air temperatures, soil temperature and air temperature become decoupled due to the low thermal conductivity of the overlying snowpack, and effect which can be observed in plots of $x$ and $y$ over time. Similarly, due to the greater diurnal variability of air temperature relative to soil temperature seen in Fig. 1 left, observations of peak daily air temperature likely do not correspond with as substantial of a peak in daily soil temperature. When considered over all values of $x$, the slope of $f(x)$ changes shape at air temperatures of $x=-5^{\circ} \mathrm{C}$ and $x=20^{\circ} \mathrm{C}$, and is most strongly positive over intermediate values of $x$. In other words, if the data set were to be separated into three bins according to these $x$ values, we could expect that the coefficients from the linear regressions would be largest and 

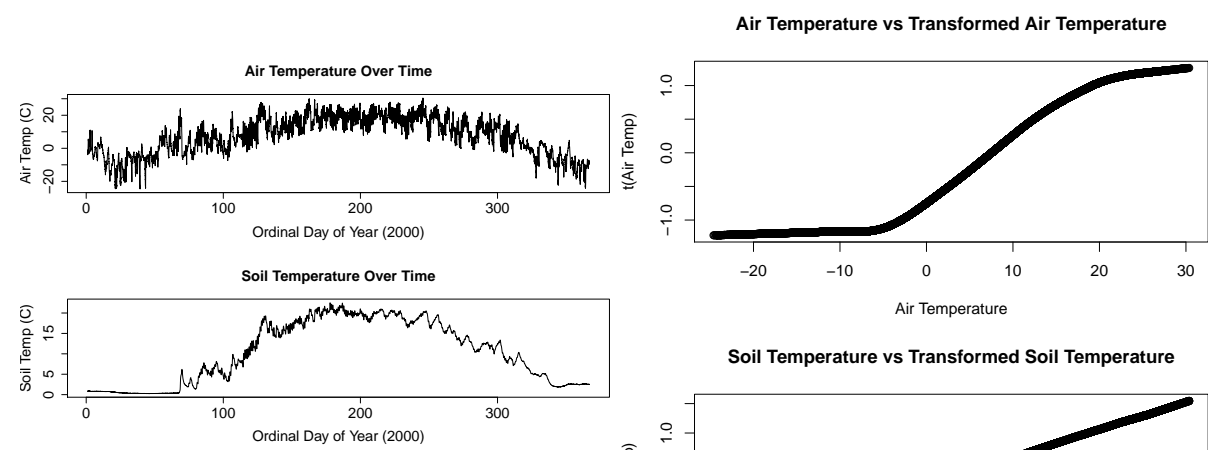

Soil Temperature vs Transformed Soil Temperature
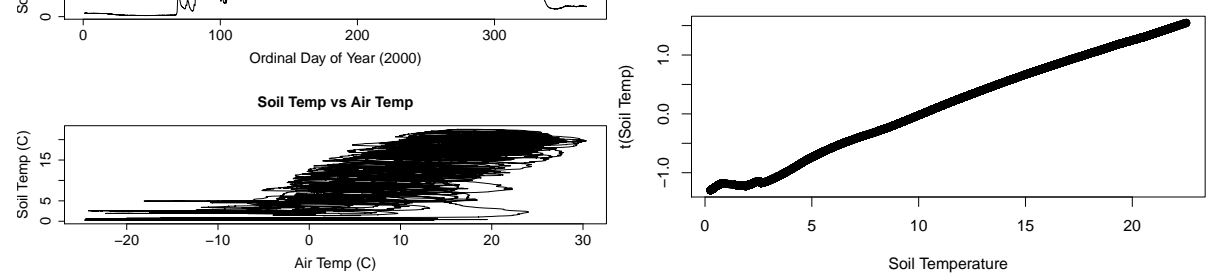

Fig. 1. First example illustrating the application of the ACE algorithm to input data (left $-x$ over time, $y$ over time, $x$ vs. $y$ ), and the resulting point pair output (right - top: $[x, f(x)]$; bottom: $[y, g(y)]$ ).
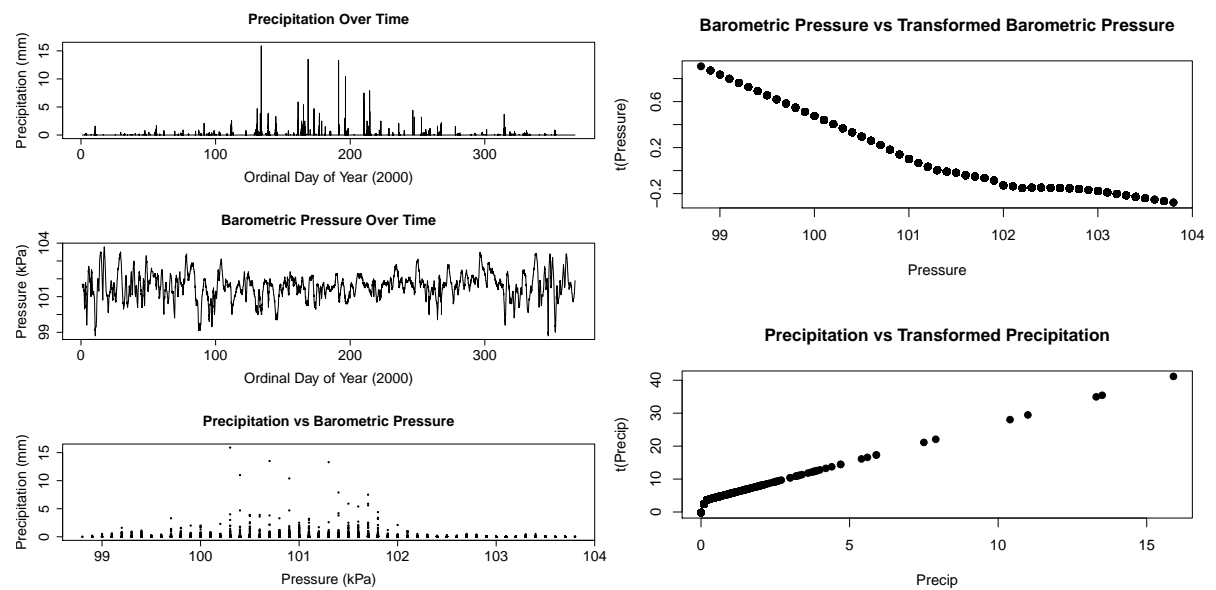

Fig. 2. Second example illustrating the application of the ACE algorithm to input data (left $-x$ over time, $y$ over time, $x$ vs. $y$ ), and the resulting point pair output (right - top: $[x, f(x)]$; bottom: $[y, g(y)]$ ).

most positive at intermediate values of air temperature, and smallest over the coldest values of air temperature.

Likewise, the ACE technique can be applied to find associations within data sets that are not immediately apparent in exploratory plots. When precipitation from a tipping bucket $(x)$ and barometric pressure (y) are plotted over time (Fig. 2 left), precipitation shows spikes with distinct events whereas barometric pressure varies with greater frequency. As a result, no clear similarity is shown in these plots over time, or when precipitation is plotted against barometric pressure. Point pair output from the ACE approach (Fig 2 right) indicates a negative approximately piece-wise linear association between barometric pressure and its transformed values $[x, f(x)]$, and a positive approximately piece-wise linear association between precipitation and its transformed values $[y, g(y)]$. ACE output therefore elucidates the tendency for greater quantities of precipitation to be received at lower barometric pressures, an association which is strongest at the lowest levels of barometric pressure.

These two simple examples were specifically selected such that the associations between $x$ and $y$ could be easily identified with and without ACE (Fig. 1), and such that the associations between $[x, f(x)]$ and between $[y, g(y)]$ could be described as linear (Fig. 2). Conversely, when the ACE approach is applied to assess associations in the GlobSnow SWE and NTSG AMSR-E Land Parameter data sets, the relationships are complex, and nonlinear. Likewise, the shape and strength of associations shown in plots of $[x, f(x)]$ and $[y, g(y)]$ cannot be visually interpreted from plots of $[x, y]$. The ACE technique therefore provides insights into associations between $x$ and $y$ that could not be gained through the application of techniques that rely on assumptions about the underlying shape of associations. 

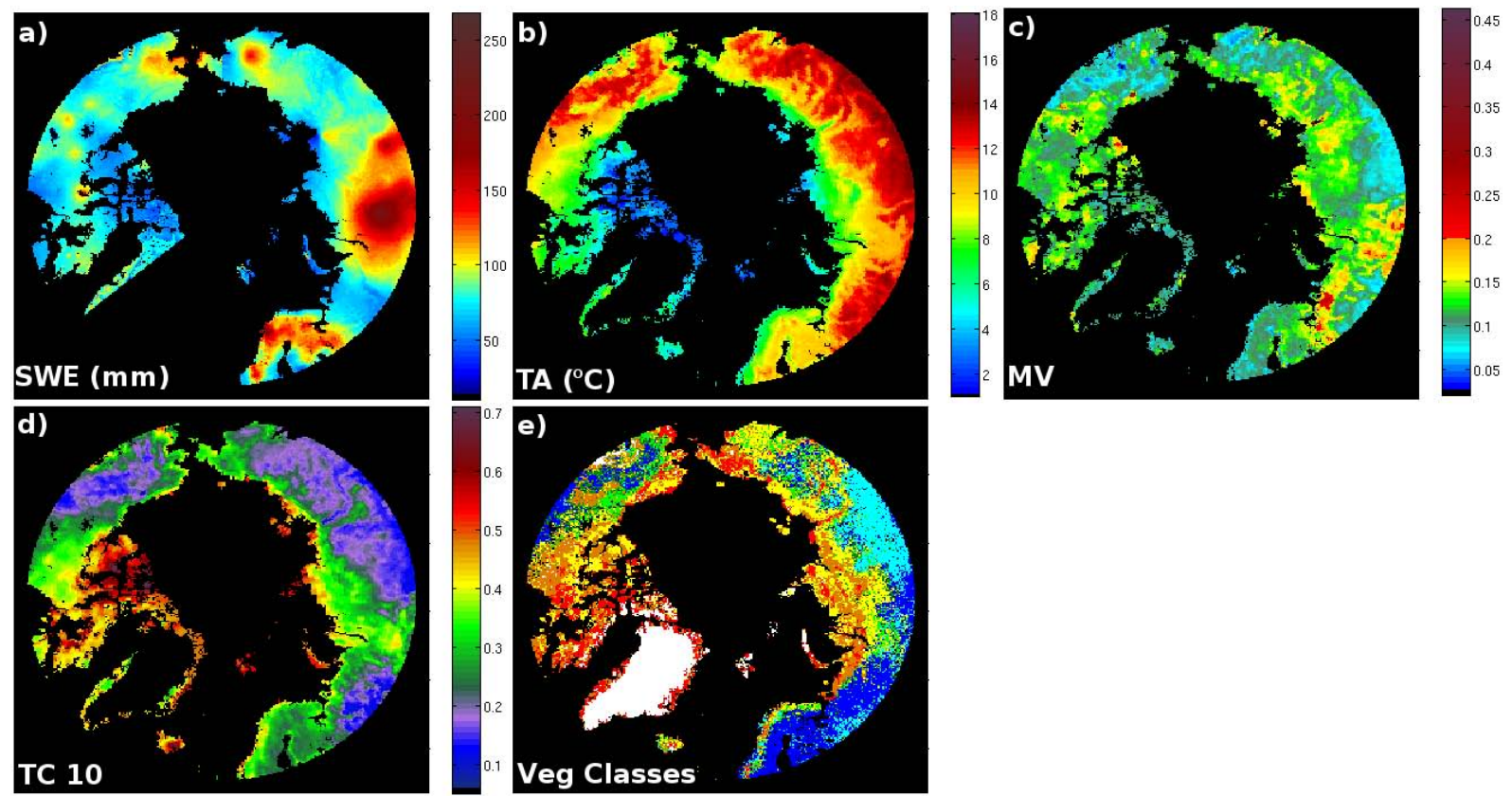

Fig. 3. Pan-Arctic (north of $60^{\circ}$ ): (a) mean 2003-2008 snow season GlobSnow snow water equivalent (SWE); (b-d) mean 2003-2008 NTSG growing-season air temperature (TA), volumetric soil moisture at $2 \mathrm{~cm}(\mathrm{MV})$, and vegetation transmissivity at $10.7 \mathrm{GHz}$ (TC10); and (e) vegetation classes used in this study, as described in Table 1.

In order to demonstrate how plots in this paper were analyzed, a detailed description is provided here of the article's first ACE point pair plot created from pan-Arctic AMSR-E derived observations. Figure 4a shows the shape of the associations between NTSG AMSR-E growing-season air temperature TA and its transformation $\mathrm{t}(\mathrm{TA})$ (Fig. 4a left), as well as the paired associations between GlobSnow SWE and its transformation $\mathrm{t}(\mathrm{SWE})$ (Fig. 4a right) in evergreen forests. Examining this figure can provide insights into the shape of the associations between growing-season air temperature and SWE. Each plot is composed of three lines which indicate the shape of these associations over three time periods:

- Mean annual SWE and mean annual TA (black)

- End of snow season SWE and start of growing-season TA (red,"spring")

- End of growing-season TA and start of snow season SWE (blue, "autumn")

When examining plots of TA vs. transformed TA (Fig. 4a left), it is clear that an approximately linear monotonically increasing transformation is selected to describe the associations between TA and t(TA) over mean annual and autumn time periods. Over spring time periods, an approximately linear monotonically increasing function is selected for locations with warm $\left(>5^{\circ} \mathrm{C}\right)$ air temperatures at the start of the growing season. Figure 4a right shows an inverse, approximately linear association to exist between SWE and $t(S W E)$ in spring and autumn. When the findings from Fig. 4a left and Fig. 4a right are jointly considered, it can be inferred that among all pan-Arctic evergreen sites, those that had relatively greater snow accumulation or more rapid snow onset at the start of the snow season also had colder temperatures at the end of the preceding snow seasons. Similarly, among evergreen sites with an average $\mathrm{TA}>5{ }^{\circ} \mathrm{C}$ at the start of the snow season, sites which were relatively colder at the start of the growing season had more snow accumulation at the end of the snow season, or underwent more rapid snowmelt. When examining the shape of the black lines describing mean annual SWE vs. mean annual $t(S W E)$, a point of inflection at $\approx 115 \mathrm{~mm}$ can be clearly seen. A positive association between SWE and TA therefore exists over regions with mean annual $S W E \geq 115 \mathrm{~mm}$, and a negative association between SWE and TA exists over regions with mean annual $\mathrm{SWE} \leq 115 \mathrm{~mm}$. All remaining plots in this paper were examined and analyzed in a similar way, and then discussed in context of in situ findings.

\section{Methodology}

GlobSnow SWE and NTSG AMSR-E Land Parameter data sets were first prepared for analysis and partitioned into vegetation classes. An exploratory analysis was conducted to examine the linear spatial relationships between data sets. The modern nonparametric method of Alternating Conditional Expectations (ACE) was then applied to examine the potentially nonlinear pan-Arctic linkages between SWE and growing-season air temperature, soil moisture and vegetation transmissivity. 

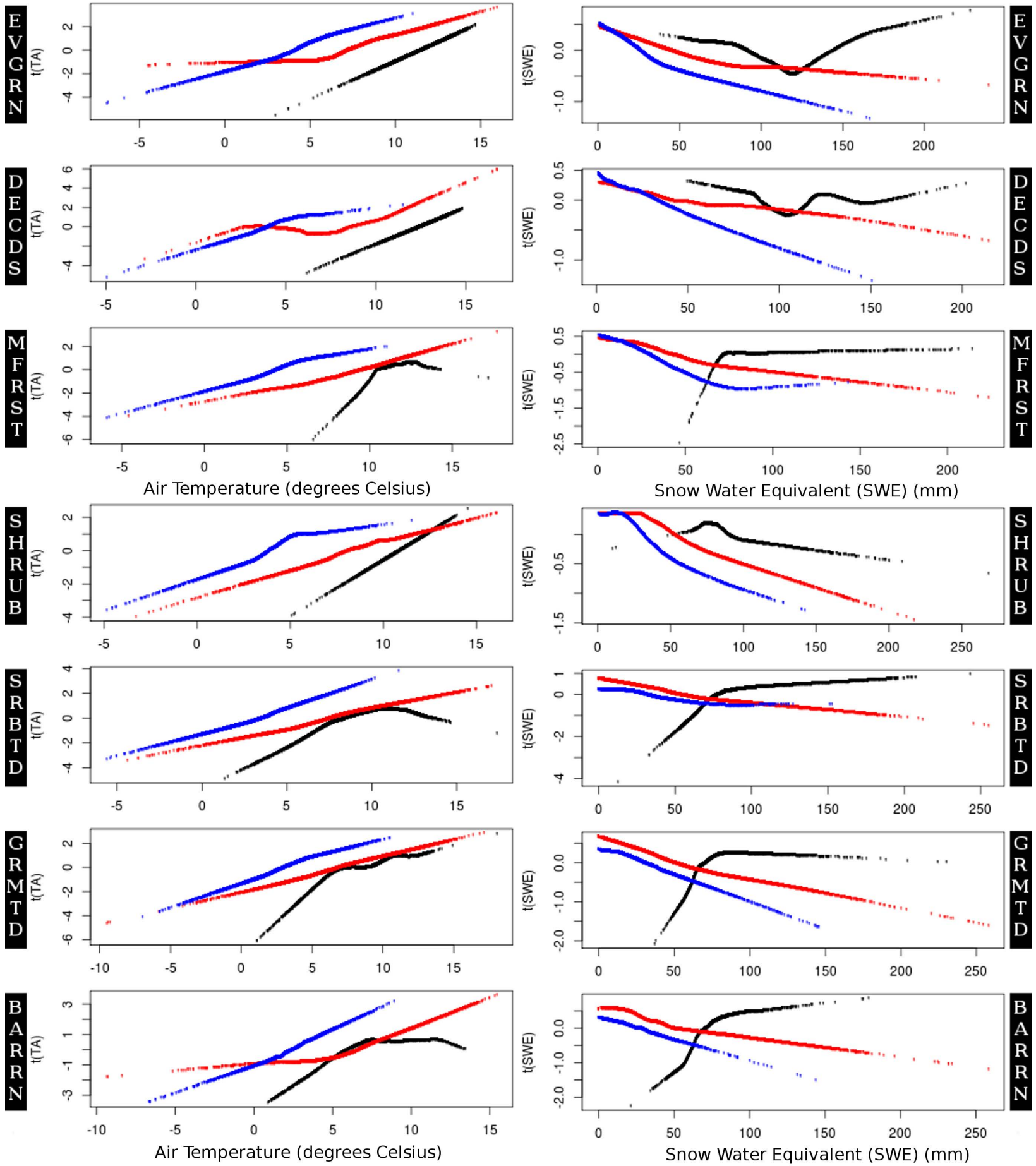

Fig. 4. a-c: Point pair output from the ACE algorithm indicating associations between air temperature (TA) and SWE ([TA, $t$ (TA)] and [SWE, $t$ (SWE)]) over three time periods: mean annual (black), 30 days preceding and 30 days following snowmelt (red), and 30 days preceding and 30 days following snow onset (blue). Results are indicated separately for all forested vegetation classes. d-g: Point pair output from the ACE algorithm indicating associations between air temperature (TA) and SWE ([TA, $t$ (TA)] and [SWE, $t$ (SWE)]) over three time periods: mean annual (black), 30 days preceding and 30 days following snowmelt (red), and 30 days preceding and 30 days following snow onset (blue). Results are indicated for separately for all non-forested vegetation classes. 

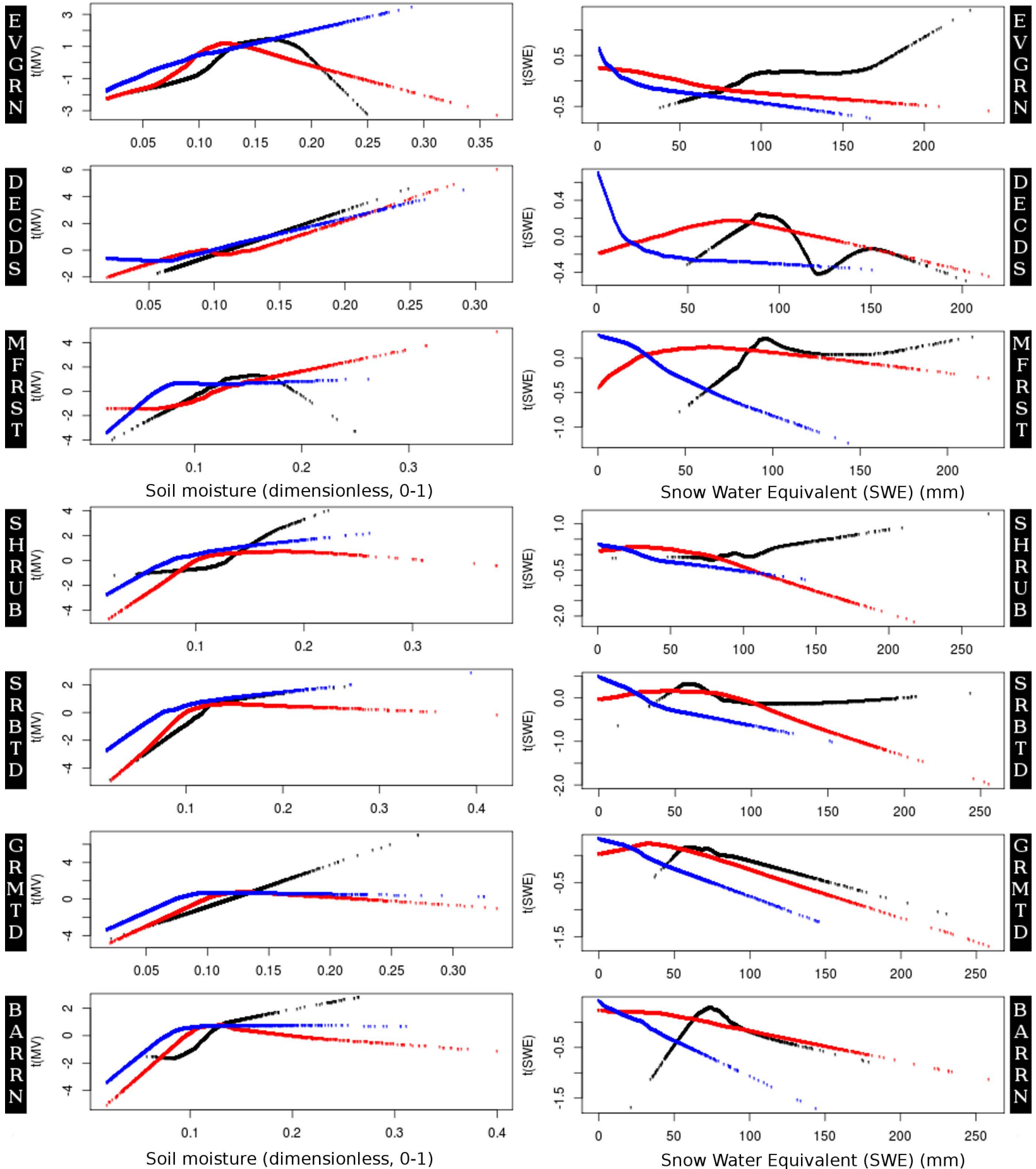

Fig. 5. a-c: Linkages between SWE and volumetric soil moisture (MV), as indicated by the optimal transformations identified using the ACE approach. The point pairs $[\mathrm{MV}, t(\mathrm{MV})]$ and [SWE, $t(\mathrm{SWE})]$ were independently calculated for each forest vegetation class shown here. Associations between mean 2003-2008 values are shown in black, and associations in "spring" and "autumn" are shown in red and blue. d-g: Linkages between SWE and volumetric soil moisture (MV), as indicated by the optimal transformations identified using the ACE approach. The point pairs $[\mathrm{MV}, t(\mathrm{MV})]$ and [SWE, $t(\mathrm{SWE})]$ were independently calculated for each non-forest vegetation class shown here. Associations between mean 2003-2008 values are shown in black, and associations in "spring" and "autumn" are shown in red and blue. 


\subsection{Data preparation}

Initial data preparation consisted of identifying the start and end dates of the snow season and growing seasons independently for each $25 \mathrm{~km}$ pixel, and for each year (2003-2008), as defined by the NTSG and GlobSnow products. The NTSG AMSR-E Land Parameters product is available only during the growing season. Estimates that occur in ice-covered, snow-covered, or precipitating conditions were eliminated from the data set by the NTSG using AMSR-E $36.5 \mathrm{GHz}$ observations and the Kim et al. (2011) algorithm (Jones and Kimball, 2010c). Conversely, the GlobSnow product is available only when the ground is frozen and snow is dry. Established techniques exist for using passive microwave observations to differentiate wet/dry snow (Stiles et al., 1980), and frozen/unfrozen ground (Zhang and Armstrong, 2001). In the GlobSnow SWE product, the melt-detection algorithm from Takala et al. (2009) is applied to help ensure estimates are provided only over dry snow. For further information on the NTSG Land Parameters and GlobSnow satellite passive microwave-derived products, please refer to Appendix A.

Observations from the NTSG Land Parameters product were only used during the period of time when the ground was unfrozen and snow-free according to both the NTSG and GlobSnow products. Conversely, the GlobSnow observations of SWE were only used for the period of time when the ground was frozen and dry snow was present, ranging from the date in autumn when SWE $>0 \mathrm{~mm}$ was first observed up until the date in spring when the last observation of SWE $>0 \mathrm{~mm}$ was recorded. The dates for the start and end of the growing and snow seasons were determined independently for each satellite-derived product, for each year, and for each individual pixel. Across the pan-Arctic region, and over all years, the snow season from GlobSnow and growing season from NTSG AMSR-E Land Parameters represent temporally distinct, non-overlapping time periods.

After the start and end dates of the snow and growing seasons were identified, mean values could be calculated for each pixel over three time periods. Mean (2003-2008) values for the snow and growing-season parameters were first separately calculated for each variable. Then, in order to determine mean values for each parameter at the start and end of the snow/growing seasons, a thirty-day range was selected as a temporal averaging window. Thirty days was selected because this represents a time period over which vegetation, snow, soil moisture and snow all generally tend to undergo seasonal changes at the start/end of the snow/growing seasons over many Arctic and boreal sites (Olsson et al., 2003; Serreze and Barry, 2005; Bonan, 2002). An identical time window was selected for all pan-Arctic pixels in order to allow pan-Arctic comparisons to be made.

Mean values for the start/end of the snow/growing seasons were calculated separately for each pixel and for each year, using the start and end dates for each season, as previously described. ACE comparisons over mean (2003-2008) time periods consider only one value for each pan-Arctic pixel, whereas comparisons at the start/end of the snow/growing seasons assess these linkages using each of the annual values calculated between 2003 and 2008. In this way, the general tendencies of each location can be assessed using the mean 2003-2008 values, and the potential influences of both typical and anomalous snow/growing-season values on the following snow/growing season can be examined.

\subsection{Vegetation classes}

As vegetation classes are often used to describe snow and growing-season characteristics of the land surface, associations between snow and growing-season variables were analyzed within seven Arctic vegetation classes defined using two well established categorizations: the SYNMAP (Jung et al., 2006) and the Circumpolar Arctic Vegetation Map (CAVM) (Walker et al., 2005). As CAVM is only available north of the tree line, SYNMAP was first used to classify the entire pan-Arctic, but was substituted with CAVM categorizations where available. The resulting 67 classes were then reorganized into seven vegetation classes shown in Table 1. Each $25 \mathrm{~km}$ pixel in the NTSG AMSR-E Land Parameter and GlobSnow data sets was then classified according to its fractional vegetation class from the upsampled CAVMSYNMAP classification.

In order for the analysis to proceed, it was important to first ensure that the aforementioned vegetation classes represent distinct populations of SWE, soil moisture, air temperature and vegetation transmissivity, and that the interannual variability of each land surface characteristic was small enough that mean 2003-2008 values could be analyzed. The heterogeneity of distributions of AMSR-E derived variables was assessed between years and between vegetation classes using Levene's test (Levene, 1960). Levene's test was selected because it provides an assessment of the deviation of an observation from a group mean, is robust to non-normality, and has been used for a variety of scientific applications, including environmental sciences (Gatswirth et al., 2009). Findings indicated that heterogeneity of variances existed across vegetation classes ( $p$ value $<10^{-5}$ ) (Table 2), and that homogeneity of variances existed between years $(0.5 \leq p$ value $\leq 0.99)$. Analysis could therefore proceed by aggregating mean 2003-2008 values, and by assessing linkages separately for each vegetation class. Regions which were identified by the NTSG AMSR-E Land Parameter product as having $>50 \%$ fractional cover of open water, or which were identified as permanent snow, ice or water by the CAVM/SYNMAP classes, were masked out from analysis. 

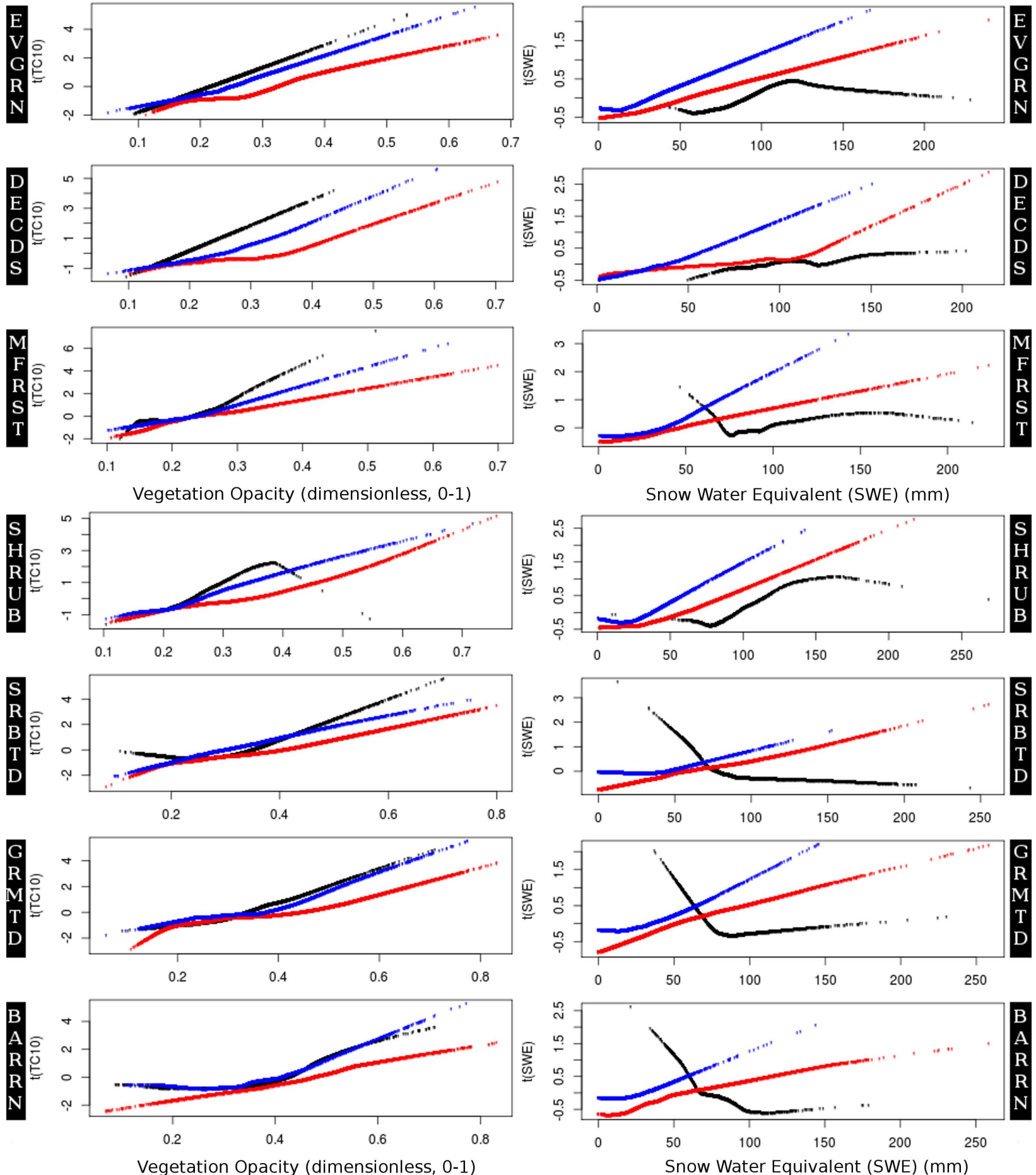

Fig. 6. a-c: Associations between satellite estimates of vegetation transmissivity at $10.7 \mathrm{GHz}$ (TC10) and SWE over seven vegetation classes, and three time periods: mean 2003-2008 (black), before and after snowmelt (red), and preceding and following snow onset (blue). Each plot indicates the point pairs [TC10, $t(\mathrm{TC} 10)]$ and [SWE, $t(\mathrm{SWE})]$ identified using the ACE technique for all forest vegetation classes. d-g: Associations between satellite estimates of vegetation transmissivity at $10.7 \mathrm{GHz}$ (TC10) and SWE over seven vegetation classes, and three time periods: mean 2003-2008 (black), before and after snowmelt (red), and preceding and following snow onset (blue). Each plot indicates the point pairs $[\mathrm{TC} 10, t(\mathrm{TC} 10)]$ and $[\mathrm{SWE}, t(\mathrm{SWE})]$ identified using the ACE technique for all non-forest vegetation classes. 
Table 1. Aggregation of forest SYNMAP and CAVM vegetation classes into a categorization that divides the pan-Arctic into seven broad vegetation classes: evergreen forest (EVGRN), deciduous forest (DECDS), mixed forest containing shrubs or grasses (MFRST), shrubdominated region (SHRUB), graminoid tundra (GRMTD), shrub tundra (SRBTD), barren vegetated region (BARRN). Regions of water or permanent snow and ice (MASKD) are excluded from the analysis.

\begin{tabular}{|c|c|c|}
\hline Veg class & Source & Description \\
\hline EVGRN & SYNMAP & Trees needle evergreen; trees broad evergreen; trees mixed evergreen \\
\hline DECDS & SYNMAP & $\begin{array}{l}\text { Trees needle deciduous; trees needle mixed; trees broad deciduous; } \\
\text { Trees broad mixed; trees mixed deciduous; trees mixed mixed }\end{array}$ \\
\hline MFRST & SYNMAP & Trees and shrubs; trees and grasses; trees and crops; crops \\
\hline SHRUBS & SYNMAP & Shrubs; shrubs and crops \\
\hline SRBTD & SYNMAP & Shrubs and barren \\
\hline SRBTD & CAVM & $\begin{array}{l}\text { Prostrate dwarf-shrub, herb tundra; erect dwarf-shrub tundra; } \\
\text { Low-shrub tundra }\end{array}$ \\
\hline GRMTD & SYNMAP & Grasses; grasses and crops \\
\hline GRMTD & CAVM & $\begin{array}{l}\text { Rush/grass, forb, cryptogam tundra; graminoid, prostrate dwarf-shrub, } \\
\text { forb tundra; } \\
\text { Prostrate/hemiprostrate dwarf-shrub tundra; nontussock sedge, } \\
\text { dwarf-shrub, moss tundra; tussock-sedge, dwarf-shrub, moss tundra }\end{array}$ \\
\hline BARRN & SYNMAP & Grasses and barren; barren \\
\hline BARRN & CAVM & $\begin{array}{l}\text { Cryptogam, herb barren; cryptogam barren complex (bedrock); } \\
\text { Sedge/grass, moss wetland; sedge, moss, dwarf-shrub wetland; } \\
\text { Sedge, moss, low-shrub wetland; noncarbonate mountain complex; } \\
\text { Carbonate mountain complex }\end{array}$ \\
\hline MASKD & SYNMAP & Urban; Snow and ice \\
\hline MASKD & CAVM & Nunatak complex; glaciers; water; lagoon \\
\hline
\end{tabular}

Table 2. Results from Levene's test examining homogeneity of variances of all variables within seven vegetation classes (Table 1), and a class containing permanent snow and ice which is masked from analysis (MASKD). These variables are air temperature (TA), volumetric soil moisture (MV), vegetation transmissivity at $10.7 \mathrm{GHz}$ (TC10), and snow water equivalent (SWE). All $p$ values are $<$ $10^{-5}$.

\begin{tabular}{lllll}
\hline & TA & MV & TC10 & SWE \\
\hline EVGRN & 2.52 & $1.06 \times 10^{-3}$ & $4.26 \times 10^{-3}$ & 898 \\
DECDS & 1.92 & $9.25 \times 10^{-4}$ & $3.76 \times 10^{-3}$ & 556 \\
MFRST & 1.77 & $8.35 \times 10^{-4}$ & $3.23 \times 10^{-3}$ & 620 \\
SHRUB & 2.46 & $8.27 \times 10^{-4}$ & $4.76 \times 10^{-3}$ & 675 \\
GRMTD & 5.77 & $6.71 \times 10^{-4}$ & $1.13 \times 10^{-2}$ & 790 \\
SRBTD & 4.73 & $4.90 \times 10^{-4}$ & $1.03 \times 10^{-2}$ & 437 \\
BARRN & 6.21 & $6.67 \times 10^{-4}$ & $1.20 \times 10^{-2}$ & 327 \\
MASKD & 6.52 & $5.56 \times 10^{-4}$ & $8.71 \times 10^{-3}$ & 279 \\
\hline Test statistic & 48.4 & 24.5 & 67.1 & 22.3 \\
\hline
\end{tabular}

\subsection{Exploratory analysis}

A brief exploratory analysis of mean values for each variable over the 2003-2008 time period (Fig. 3a-f) indicated that growing-season air temperature and vegetation opacity display a latitudinal gradient, with cooler temperatures and less vegetation at high latitudes, likely due to the temperature dependence of Arctic vegetation (Hare, 1968; Ritchie and Hare,
1971). Soil moisture and snow water equivalent show greater spatial variability due to topographic, meteorological, atmospheric, and land surface influences (Callaghan et al., 2011; Serreze and Barry, 2005).

Greater values of SWE occur in regions where more snowfall occurs, where windblown snow is accumulated, or where snowmelt during the snow season is less frequent or less substantial. Ideally, these contributions to SWE could be partitioned so that the linkages between growing-season variables with snowfall, snowmelt and windblown snow deposition could be analyzed. However, current estimates of precipitation are presently unreliable at high latitudes, especially during the snow season, and the amount of snow must therefore be examined in terms of SWE alone. It is important to note that mean values of SWE at the start and end of the snow season are thus indicative of both accumulation as well as the speed of snow onset/melt. At the start and end of the snow season, mean values of SWE are greater at sites where snowmelt and snow accumulation occur more rapidly, as these have fewer days with low reported values of SWE. Similarly, low values of SWE at the start or end of the snow season are indicative of less snow accumulation, or slower snow onset or melt. Although a brief exploratory analysis was conducted of all variables at the start/end of the snow/growing seasons, associations between these variables could not be discerned visually. The ACE technique instead provides insights into the shapes of these associations, and 
how they vary according to the time period and vegetation class over which they are examined.

\subsection{Preliminary regression analysis}

Preliminary regression analysis consisted of applying linear regression and principal component analysis (PCA) to assess the possibility of linear relationships between snow and growing-season values. However, it is likely that the assumption of linearity cannot be fulfilled, and in addition, application of the Shapiro-Wilk test (D'Agostino and Stephens, 1986) indicated that the soil moisture and air temperature data sets had non-normal distributions at high latitudes ( $p$ values $<0.01$ ). Linear regression and PCA therefore do not represent suitable techniques for examining associations between the GlobSnow SWE and NTSG land surface variable data sets, but the findings from these approaches are of interest because PCA and linear regression are widely used to examine environmental linkages. The derived $R^{2}$ from classical single and multiple linear regressions (Table A1) along with the multiple linear regression of SWE vs. factor scores obtained from the principal component analysis (PCA) of air temperature (TA), volumetric soil moisture (MV), and vegetation canopy transmissivity (TC) (Table A2) indicated that the linear associations between SWE and growing-season variables were very weak or non-existent.

Conversely, a multivariate ACE analysis of these associations yielded much greater $R^{2}$ values for every vegetation class and time period relative to the linear regression (Table B1), while a univariate ACE analysis indicated highly significant ( $p$ value $<10^{-5}$ ) pairwise associations for all vegetation classes, variables and time periods. Moreover, the $p$ values of all coefficients in multivariate ACE analysis were also highly statistically significant. As a result, we can conclude that there exists no collinearities in the nonparametrically transformed growing-season variables when these are transformed to linearize their associations with transformed values of SWE. The findings from this stage of preliminary regression analysis strongly support the employment of the nonparametric ACE technique to explore the nonlinear associations within this data set.

\subsection{ACE}

The ACE approach was applied to determine the strength and directionality of the associations between SWE and growingseason values for each vegetation class and time period separately. Associations between these data sets could therefore be examined despite their lack of temporal overlap by comparing: (1) mean growing season with snow season values; (2) mean values of SWE over the last thirty preceding the onset of snowmelt with mean land surface values over the first thirty days with a snow-free and unfrozen land surface following snowmelt; and (3) mean land surface variables over the last thirty days of the growing season before snow onset with mean values of SWE occurring after the first observation of dry snow on frozen ground after the end of the growing season. These time periods are referred to as "mean", "spring" and "autumn", respectively, throughout the paper. For a thorough description of study limitations, please refer to Appendix B. All ACE analysis was conducted in R (?) using the acepack library (Spector et al., 2013).

\section{Results and Discussion}

Findings from the ACE analysis of associations between SWE, air temperature, soil moisture and vegetation transmissivity are presented and discussed below in relation to in situ observations. The results have been divided into separate sections according to the growing-season values associated with SWE, with subsections corresponding to different time periods. Each section contains tables showing the strength of associations ( $R^{2}$ value) of ACE transformed SWE and growing-season values (Table B1), and plots indicating the optimal transformations of SWE and growing-season values according to the seven vegetation classes (Figs. $4 \mathrm{a}-\mathrm{c}, 4 \mathrm{~d}-\mathrm{g}$, $5 \mathrm{a}-\mathrm{c}, 5 \mathrm{~d}-\mathrm{g}, 6 \mathrm{a}-\mathrm{c}$ and $6 \mathrm{~d}-\mathrm{g})$.

\subsection{Air temperature and SWE}

At tundra sites, a positive, nonlinear association exists between mean annual SWE and mean growing-season air temperatures such that sites which tend to be slightly warmer tend to accumulate more snow than cooler sites. Yet, sites that tend to be warmer at the start and end of the growing season tend to contain less snow during initial snow onset and final snowmelt each year.

\subsubsection{North of the treeline, greater mean annual SWE with warmer growing seasons}

The associations between mean 2003-2008 SWE and growing-season air temperature at tundra sites are nonlinear. As a result, findings from the linear regression approach indicate weaker associations at tundra sites $\left(R^{2}=0.04\right.$ 0.20) (Table A1) than detected by the ACE transformations $\left(R^{2}=0.20-0.38\right)$ (Table $\left.\mathrm{B} 1\right)$. The associations between growing-season air temperature and SWE are weaker over forested regions, likely due to seasonal discrepancies in the mean growing season and mean snow season air temperatures (Overland et al., 1997; Rigor et al., 2000; Adams et al., 2000; Serreze and Barry, 2005). The following analysis therefore focuses mainly on the associations observed north of the treeline, although all plots can be found in Figs. $4 \mathrm{a}-\mathrm{c}$ and $4 \mathrm{~d}-\mathrm{g}$.

Examinations of Fig. 4e-g indicate sharp, positive transformations applied to low values of SWE $(<75 \mathrm{~mm})$. Likewise, these plots show that the positive association between air temperature and SWE at these locations exists for sites with a mean annual growing-season temperature of $<10^{\circ} \mathrm{C}$. 
Analysis of the ACE transformations provides an important source of information for understanding these linkages. Arctic tundra regions are characterized by very cold temperatures during the snow season that limit the availability of water vapor and the rate of precipitation (Bonan, 2002; Serreze and Barry, 2005), thereby resulting in diminished accumulation of snow, and it is likely that the influence of diminished water vapor explains the association between SWE and growing-season air temperature. Analysis of the ACE transformations therefore indicates that in tundra regions with $<75 \mathrm{~mm}$ of SWE and mean growing-season air temperatures of $0-10^{\circ} \mathrm{C}$, sites that tend to have slightly warmer air temperatures will likely tend to accumulate greater quantities of SWE.

\subsubsection{Warmer spring/autumn temperatures and less SWE}

ACE analysis indicated that weak, approximately linear associations exist between warmer air temperatures and diminished SWE at the start and end of the snow season (Table B1). Regions that tended to be warmer at the start and end of the snow season therefore tended to have less SWE at the start and end of the snow season, or more gradual snow onset or melt.

The associations between autumn SWE and air temperature were found to be weaker over tundra regions (ACE $\left.R^{2}=0.06-0.10\right)$ than forested regions (ACE $R^{2}=0.14$ 0.25 ). As forest soils have been observed to be warmer and to freeze more gradually than tundra soils at the start of the snow season (Rouse, 1984; Smith et al., 1998), it is likely that the influence of antecedent growing-season air temperatures on the capacity of a dry snowpack to develop at the start of the snow season would be stronger over regions without permafrost.

\subsection{Soil moisture and SWE}

The ACE transformed associations between mean annual SWE and mean growing-season soil moisture are weak across all vegetation classes (0.02-0.09) (Table B1) due to the large number of confounding factors affecting the association between soil moisture and SWE. The results must therefore be interpreted with caution. However, although the associations between mean annual values are generally weak and nonlinear, a positive association exists between mean annual SWE and soil moisture at sites with very low SWE $(<90 \mathrm{~mm})$ and low soil moisture $(<0.17)$. The observed thresholds correspond with thresholds observed in situ. When considered over the start/end of the snow/growing seasons, the associations are relatively weak across all vegetation classes $(0.02-0.17)$. Despite challenges in elucidating these associations due to confounding factors, it is interesting to note that a weak inverse association appears to exist between SWE and soil moisture in spring and autumn (Figs. 5a-c and 5d-g) which has also been observed in situ.

\subsubsection{Mean annual SWE and soil moisture}

The relationships between mean annual SWE and soil moisture are weak, nonlinear, and vary according to vegetation class over which they are examined. Seasonal differences in precipitation patterns (Serreze and Barry, 2005), as well as confounding factors such as soil freeze patterns, vegetation (Hardy et al., 2001; Johnsson and Lundin, 1991), ponds (French and Binley, 2004), topography (Burt and Butcher, 1985) and soil type (Janowicz et al., 2003; Williams and Ratsetter, 1999) are likely to limit the strength of the associations between SWE and soil moisture, and limit the extent to which these associations can be regionally generalized. Nevertheless, the ACE transformations indicate that positive associations exist between mean annual SWE and soil moisture in forested and barren regions that accumulate little snow $(\mathrm{SWE}<90 \mathrm{~mm})$ and have low soil moisture $(<0.17)$. Similarly, a positive association between soil moisture and SWE is observed over shrub-dominated regions for all values of SWE and soil moisture, and over mixed forest regions accumulating less than $100 \mathrm{~mm}$ of SWE.

The influence of very low SWE $(<100 \mathrm{~mm})$ has been studied in situ at barren (Ayres et al., 2010) and hardwood (Hardy et al., 2001) sites. Findings indicated that snow removal at the hardwood site resulted in greater soil heat loss, and therefore increased the proportion of ice in soil. As a result, snowmelt infiltration and soil moisture were reduced in plots where snow was removed (Hardy et al., 2001). Similarly, experimental manipulation of snow accumulation at a polar desert indicated that sites where greater quantities of snow were accumulated tended to have greater levels of soil moisture during the following growing seasons relative to paired control sites (Ayres et al., 2010). In the previously described experimental plots simulating low snow conditions, the barren site accumulated 10-50 $\mathrm{mm}$ of SWE and the hardwood site accumulated $80-100 \mathrm{~mm}$ of SWE. As a result, these studies indicated that diminished SWE led to diminished soil moisture in barren and hardwood plots with $<100 \mathrm{~mm}$ of SWE. Therefore, although the $R^{2}$ values from this study indicate that a weak and nonlinear association exists between SWE and soil moisture across all vegetation classes, the ACE approach has elucidated similar thresholds and linkages as those which have been recorded in situ.

The ACE approach also indicated that a greater mean annual SWE is associated with greater soil moisture across all values observed over shrub-dominated regions, and at low $(<0.15)$ levels of soil moisture in evergreen forests and graminoid tundra. Similarly, in a study conducted at the regional scale, anomalies in maximum annual snow depth and soil moisture were found to be associated in a semiarid region of Eurasia north of the Caspian-Aral seas (Shinoda, 2001). This region has maximum annual values of $<150 \mathrm{~mm}$ 
of SWE, and is classified as evergreen and deciduous forest in the present study. In years where snow accumulation tended to be greater, snowmelt onset was found to occur later and larger values of soil moisture were observed during the following growing season. The finding by Shinoda (2001) that SWE and soil moisture tend to be associated over semiarid evergreen regions is therefore consistent with findings from this study, which indicate positive associations between mean annual SWE and soil moisture at sites that tend to receive less mean annual SWE and tend to have low soil moisture.

\subsubsection{SWE and soil moisture in spring and autumn}

The associations between soil moisture and SWE are weak when examined over thirty-day time periods in spring (ACE $R^{2}=0.02-0.17$ ) and autumn (ACE $R^{2}=0.06-0.12$ ). Just as with the associations between mean annual SWE and soil moisture, the presence of multiple confounding factors as well as the temporal gap between liquid and solid precipitation mean that the associations found from this analysis are weak and must be interpreted cautiously. At mixed forest and deciduous sites, ACE transformations indicates that a positive association exists between spring soil moisture and SWE at sites with low $(<75 \mathrm{~mm})$ snow accumulation. Similarly, results from a snow depth manipulation experiment conducted in a hardwood forest indicated diminished soil moisture following snowmelt in a hardwood forest with very low snow accumulation (Hardy et al., 2001).

The associations between SWE and soil moisture over remaining vegetation classes and time periods are slightly more complex. Although snow accounts for a large portion of annual precipitation, little of the moisture released through snowmelt in the Arctic is retained by soil (Willis et al., 1961) due to rapid snowmelt, runoff and outflow (Hardy et al., 2001; Johnsson and Lundin, 1991). For example, in a study at the Imnaviat Creek Arctic headwater, snow accumulation in spring accounted for $28-40 \%$ of annual precipitation, only $10-19 \%$ of the liquid water arising from snowmelt was stored in the active layer (Kane et al., 1991). Regions with greater accumulation of snow tend to contribute a larger percentage of snowmelt to runoff (Willis et al., 1961; Staple et al., 1960). It is therefore less likely that a positive association would be observed between SWE and soil moisture in spring and autumn in areas underlain by permafrost.

An inverse relationship is observed to exist between soil moisture at the end of the growing season, and the accumulation of SWE at the start of the snow season for all vegetation classes (Figs. $5 \mathrm{a}-\mathrm{c}$ and $5 \mathrm{~d}-\mathrm{g}$ ). Soil freezing occurs more slowly over wet soils than dry soils due to the influence of moisture on soil heat capacity (Willis et al., 1961; Hardy et al., 2001). As snow can only accumulate over cool soil surfaces, it is reasonable that soils which cool more rapidly at the start of the snow season may undergo greater net snow accumulation after freezing than warmer, wetter soils.
Likewise, in spring, an inverse association between soil moisture and SWE was observed over evergreen, shrub, tundra and barren regions with low $(<0.1)$ soil moisture. The portion of snowmelt that infiltrates into the soil surface relies on the rate of snowmelt, soil water, soil frost and soil drainage (Hardy et al., 2001; Johnsson and Lundin, 1991). An inverse association therefore exists between seasonal infiltration and soil moisture levels during snowmelt (Zhao and Gray, 1999). The soil frost and soil drainage patterns at the end of the snow season can also be influenced by the levels of soil moisture observed prior to soil surface freezing at the start of the snow season (Hardy et al., 2001; Suzuki et al., 2006). Soils which are drier at the start of the snow season freeze more deeply than wetter soils and also thaw out more gradually (Willis et al., 1961). Furthermore, soils with frozen upper layers have diminished infiltration due to the influence of ice on reducing soil pore size and permeability (Zhao and Gray, 1999). Therefore, since drier soils tend to freeze faster and more deeply than wet soils, more opportunity exists for snow accumulation to occur at the start and end of the snow season over dry soils because melt is less likely to occur. Soils which are more thoroughly frozen throughout the snow season are likely to receive less infiltration of snowmelt, and are therefore likely to be drier at the start of the growing season. It is interesting to note that the output from the ACE analysis appears to agree with these field-scale findings. However, the associations observed using the ACE technique are weak due to the strength and number of confounding factors. Further analysis will be required using different data sets to gain a better understanding of these linkages.

\subsection{Vegetation transmissivity and SWE}

Mean annual SWE and vegetation transmissivity generally have a negative association north of the tree line, indicating greater SWE accumulation in regions with greater surface roughness or aboveground biomass (Figs. $6 \mathrm{a}-\mathrm{c}$ and $6 \mathrm{~d}-$ g). Conversely, the association between SWE and vegetation transmissivity in forested regions tends to be positive, such that SWE accumulation is limited in areas with greater aboveground biomass. At the start and end of the snow season, vegetation transmissivity is positively associated with SWE, which indicates more rapid melt or less snow accumulation at the start and end of the snow season in regions with more vegetation.

\subsubsection{Mean annual SWE and vegetation transmissivity}

The association between mean annual SWE and mean vegetation transmissivity (2003-2008) varies according to the predominant land cover, as well as the quantity of SWE received. In Arctic regions north of the tree line with a mean SWE accumulation of $<75 \mathrm{~mm}$, an inverse association exists between vegetation transmissivity and SWE, indicating that 
locations with slightly more vegetation lost less snow to sublimation than regions with less vegetation. Shrub-dominated regions north of the tree line have often been observed to trap snow more readily than regions which are more sparsely vegetated (Pomeroy et al., 1997; Sturm et al., 2001a, b; Liston and Sturm, 2002; Essery and Pomeroy, 2004). Shrubs have greater snow-holding capacity then graminoid or barren vegetation since shrubs reduce near-ground wind speeds, thereby allowing greater deposition and less loss due to sublimation (Essery and Pomeroy, 2004; Sturm et al., 2001a; Fitzgibbon and Dunne, 1979). From the ACE analysis, it appears that this influence is strongest over regions with less SWE. Due to the nonlinearity of the association between mean annual SWE and vegetation transmissivity over tundra and barren sites, the ACE transformation is useful since it identifies the shape of this association $\left(R^{2}=0.19-0.29\right)$ whereas a linear regression approach would only have indicated that a weak linear association exists between variables $\left(R^{2}=0.06-0.15\right)$.

The association between vegetation cover and SWE may also be due in part to the influence of local precipitation on vegetation species compositions, which has previously been observed over the Brooks Range of Alaska by Evans et al. (1989). In northern regions, the health and productivity of vegetation can be compromised by very cold air, low soil temperatures and rain-on-snow events. Snow has been observed to provide vegetation with insulation from cold soil temperatures, and protection from dehydration, frost damage and high winds (Wardle, 1968; Tranquillini, 1964). Therefore, where snow accumulation is more substantial and remains on the ground for a longer time in spring, higher NDVI values have been observed (Grippa et al., 2005), which indicate greater health or quantity of aboveground biomass (Jensen, 2007).

Areas that tend to lose less snow through sublimation, and accumulate more snow through windblown deposition, also tend to accumulate greater quantities of windblown organic materials throughout the snow season (Walker et al., 2001), and undergo greater rates of organic matter decomposition throughout the snow season since they have warmer soil temperatures (Nowinski et al., 2010). Both of the aforementioned influences can lead to nutrient rich conditions in regions receiving greater accumulation of snow, which can create growing-season conditions that are conducive to plant growth. It is therefore possible that greater quantities of snow and vegetation tend to be collocated in Arctic regions due to the influence of snow on encouraging plant growth, and the influence of vegetation on encouraging snow accumulation. Spatial variability may therefore also play a role in this association, as high Arctic regions both accumulate small quantities of snow and contain little aboveground biomass.

The ACE analysis indicates that snow accumulation at low SWE $(<115 \mathrm{~mm})$ evergreen forest sites is maximized when less vegetation is present $\left(R^{2}=0.10\right)$. Likewise, field studies have found that snow accumulation is greater in clearings than coniferous forests (Golding and Swanson, 1986;
Gelfan et al., 2004), since coniferous trees intercept snowfall, and have been observed to allow $20-50 \%$ of precipitation to evaporate or sublimate Lundberg and Halldin (2001). However, although coniferous stands with dense crowns limit snow accumulation, sparser evergreen forests can encourage snow deposition (Church, 1933). Based on the findings from the ACE analysis, it appears that the effects of evergreen forests on limiting snow accumulation are strongest at lower SWE $(<115 \mathrm{~mm})$ sites, whereas at higher SWE $(>115 \mathrm{~mm})$ sites, a slightly positive association appears to exist between vegetation biomass and SWE. This could be due to the effect of dense boreal forest cover, which causes SWE to be underestimated from satellite passive microwave observations. However, it is also reasonable that wind redistribution would be a dominant process when availability of fresh snow is great, but that sublimation, interception and melt would be dominant processes when snow accumulation is limited. It is also interesting to note in this context that over deciduous forests, vegetation biomass and SWE are inversely associated over all levels of SWE.

Assessment of these associations over mixed forest and shrub classes indicates that the associations between SWE and vegetation transmissivity are intermediate between those observed over tundra regions, and forested regions. Likewise, as the vegetation classes represent fractional portions of $25 \mathrm{~km}$ pixels according to the CAVM-SYNMAP-derived classification, both the mixed forest and shrub classes contain a mixture of forest and non-forest vegetation. Over mixed forested regions, vegetation biomass and SWE are positively associated over areas with lower SWE $(<75 \mathrm{~mm})$, just as observed as a result of shrub cover over tundra regions. In shrubland areas containing large quantities of biomass and SWE, vegetation biomass and SWE are inversely associated. Conversely, in shrublands with diminished vegetation biomass, regions with greater biomass have greater SWE. Further field investigations would be required to better elucidate these drivers and clarify the dependence of these associations on the stated thresholds.

\subsubsection{In spring and autumn, slower snowmelt in areas with more vegetation}

Across all vegetation classes, positive associations of moderate strength exist between the mean values of SWE over the last thirty days of the snow season and the mean values of vegetation transmissivity over the first thirty days of the growing season (ACE $\left.R^{2}=0.19-0.31\right)$. The presence of this association indicates that regions with greater quantities of vegetation or greater surface roughness tend to contain a lower mean quantity of snow over the last thirty days of the snow season. This association is approximately linear across all vegetation classes (Figs. $6 \mathrm{a}-\mathrm{c}$ and $6 \mathrm{~d}-\mathrm{g}$ ).

Field studies have largely indicated that snow depletion in forested regions occurs more gradually in regions with greater quantities of vegetation. The rates of snowmelt in 
boreal and taiga forests have been observed to diminish with increasing canopy density (Pomeroy and Dion, 1996; Pomeroy et al., 1997; Metcalfe and Buttle, 1998; Gelfan et al., 2004). This effect is due to the influence of the forest canopy on limiting shortwave radiation received by snow, and its effect on slowing wind speeds, thereby limiting fluxes of latent and sensible heat (Metcalfe and Buttle, 1998).

When examining vegetation transmissivity over the last thirty days of the growing season against SWE over the first thirty days of the snow season, a positive, approximately linear association of moderate strength can be identified for all sites south of the tree line (ACE $R^{2}=0.17-0.30$ ). Forested sites containing greater quantities of aboveground biomass therefore tend to accumulate less snow over the first thirty days following the date of initial snowfall than sites with less biomass. Field studies have indicated that interception and sublimation by dense canopies diminish snow accumulation (Pomeroy et al., 1999, 2002; Lundberg and Halldin, 2001). The observed associations between SWE and vegetation biomass over tundra and barren regions appear weak but positive. However, to date, field studies have focused mainly on characterizing the influence of vegetation on mean annual snow accumulation, and on the magnitude and timing of snowmelt. A better understanding of these interactions could therefore be acquired through in situ observations of the effects of vegetation compositions on distributions of snow at the start of the snow season.

\section{Conclusions}

The Alternating Conditional Expectation (ACE) approach revealed nonlinear associations between passive microwavederived snow water equivalent, and growing-season air temperature, soil moisture and vegetation transmissivity. Although the drivers of snow accumulation vary according to the scale at which they are examined (Pomeroy et al., 2002), and uncertainty exists in passive microwave estimates of the Arctic land surface due to its heterogeneity and high lake fraction (Duguay et al., 2005; Rees et al., 2006; Green et al., 2012), it is interesting to note the similarity existing between the linkages, thresholds and associations found in situ and through ACE analysis of passive microwave observations (at $25 \mathrm{~km}$ resolution).

Across all vegetation classes, sites with more aboveground biomass at the start and end of the growing season tend to have lower mean values of SWE over the first and last thirty days of the snow season. Field studies have found that snowmelt occurs more gradually over barren or graminoid tundra regions with more vegetation due to shading and slowed wind speeds (Metcalfe and Buttle, 1998), and that snow accumulation is diminished over forested regions with greater canopy density due to interception and sublimation (Pomeroy et al., 2002). The ACE technique also indicated that sites with drier soils at the end of the growing season tended to accumulate more snow at the start of the snow season. Likewise, in situ observations have indicated more rapid and thorough freezing of soils which were dry at the start of the snow season (Willis et al., 1961), which could allow snow to accumulate more easily over cooler soils.

In forested regions, sites that tend to accumulate less snow also tend to have greater canopy density, as indicated by diminished vegetation transmissivity. Field studies have indicated that snow accumulation in heavily forested areas is limited due to canopy interception and sublimation (Church, 1933; Pomeroy et al., 2002). ACE analysis also indicated that within forested regions accumulating $<90 \mathrm{~mm}$ of SWE, sites with greater SWE tended to also have greater soil moisture, an observation similar to the in situ findings by Hardy et al. (2001).

In Arctic tundra regions with lower $(<75 \mathrm{~mm})$ SWE, more snow is accumulated at sites with warmer growing-season temperatures and greater biomass or surface roughness, as indicated by diminished values of vegetation transmissivity. Arctic regions with warmer annual air temperatures have greater moisture availability for snow season precipitation (Serreze and Barry, 2005), and snow is preferentially accumulated in regions with greater vegetation or surface roughness (Walker et al., 2001). Over dry $(<0.1$ soil moisture) Arctic areas, sites that have more snow at the end of the snow season tend to have wetter soils at the start of the growing season. Arctic regions that have more snow for the last thirty days of the snow season also tend to have have cooler temperatures at the start of the growing season, likely due to the rapid snowmelt undergone by cold, high latitude sites (Bonan, 2002).

Recent circumpolar predictions indicate that climate change may diminish the annual duration of snow cover and increase maximum annual SWE (Callaghan et al., 2011), and that high latitude warming and altered snow season length can affect Arctic vegetation phenology and species composition (Arft et al., 1999; Walker et al., 1999). As the ACE technique has uncovered linkages between snow and growingseason land surface variables that bear great similarity to associations observed in situ, this also suggests that climatedriven changes in soil moisture, vegetation composition and air temperature may both influence, and be influenced by, shifts in the timing and accumulation of snow.

We therefore suggest that continued monitoring of Arctic ecosystems at the field scale be accompanied by applications of the ACE technique to monitor linkages between satellite passive microwave observations of snow and growing-season variables. We also suggest that snow and growing-season remote sensing observations be included in models estimates of NEE (e.g. (Luus et al., 2013a)), since the linkages between snow/growing-season land surface characteristics vary according to the time period and vegetation class over which they are examined. 


\section{Appendix A}

\section{Data: GlobSnow SWE and NTSG AMSR-E Land Parameters}

The products compared in this study are derived from gridded Level 2A brightness temperature from the Advanced Microwave Scanning Radiometer for the Earth Observing System (AMSR-E). AMSR-E is a multichannel satellite passive microwave radiometer collecting observations at 6.925 , 10.65, 18.7, 23.836 .5 and $89.0 \mathrm{GHz}$ (Kawanishi et al., 2003). Passive microwave observations rely on estimates of microwave radiance, which increases proportionally with temperature and emissivity of a surface. Brightness temperature $\left(T_{\mathrm{b}}\right)$, the variable of observation by passive microwave instruments, is a function of the product of kinetic temperature $\left(T_{\mathrm{k}}\right)$ and emissivity $(\epsilon): T_{\mathrm{b}}=T_{\mathrm{k}} \epsilon . \mathrm{T}_{\mathrm{b}}$ is equivalent to the physical temperature of a blackbody $(\epsilon=1)$ (Jones et al., 2010d).

AMSR-E $T_{\mathrm{b}}$ has been used previously to estimate snow water equivalent (Kelly, 2009), vegetation and soil moisture (Njoku and Chan, 2005). These approaches have continued improving in accuracy and global coverage, culminating in the recent release of the AMSR-E derived data sets analyzed in this study: NTSG land parameters by Jones and Kimball (2012) and GlobSnow SWE by Luojus et al. (2009). The following subsections describe the methodologies applied by the Finnish Meteorological Institute (FMI)-led consortium and the University of Montana's Numerical Terradynamic Simulation Group (NTSG) to calculate GlobSnow SWE and land surface variables, respectively. All data are calculated from AMSR-E brightness temperature observations acquired at $6.9,10.7,18.7,23.8,36.5$ and $89.0 \mathrm{GHz}$ twice daily with native resolutions varying inversely with frequency from $5 \mathrm{~km}$ to $60 \mathrm{~km}$ (Jones and Kimball, 2010a). NTSG and GlobSnow both use NSIDC Level 2A AMSR-E data, which resamples each frequency's native resolution to that of the $6.9 \mathrm{GHz}$ frequency. The resulting product is available on a $25 \mathrm{~km} \mathrm{~km}$ EASE-Grid (Ashcroft and Wentz, 2003; Knowles et al., 2010). GlobSnow snow water equivalent uses 18.7 and $36.5 \mathrm{GHz}$ frequency data (Luojus et al., 2009). Both the GlobSnow and AMSR-E air temperature data sets have been validated against in situ and AIRS/AMSU observations, respectively (Jones et al., 2010d). Analysis in this study made use of AMSR-E land surface variables version 1.2 (Jones and Kimball, 2012) and version 0.9.1 of GlobSnow SWE (Luojus et al., 2009).

\section{A1 GlobSnow snow water equivalent (winter season)}

The snow depth and quantity of snow can be estimated from passive microwave observations as a linear function of the difference between brightness temperatures at two frequencies, such as $18 \mathrm{GHz}$ and $\mathrm{GHz}$ with horizontal polarization (Chang et al., 1987). A new data set used for SWE estimates,
GlobSnow, optimizes agreement between measured and simulated brightness temperature using forward simulation of different grain sizes.

GlobSnow SWE estimates (in $\mathrm{mm}$ ) are calculated using AMSR-E 18.7 and $36.5 \mathrm{GHz}$ data as well as meteorological data. Meteorological stations provide estimates of snow depth, which are filtered to remove spurious values and are then kriged between stations (Takala et al., 2011). In the GlobSnow algorithm, regions with thin snowpacks, snowmelt or wet snow are masked out, as wet snow acts as a microwave emitter (Armstrong and Brodzik, 2001). Snow grain size is estimated through an inversion of AMSR-E observations using the Helsinki University of Technology snow microwave emission model (Pulliainen et al., 1999). Snow water equivalent is then calculated from snow depth through knowledge of snow density. Single fixed variables are used to estimate snowpack, soil and forest characteristics. Surface roughness and soil moisture are assumed to have the same value across the entire pan-Arctic, and forest cover effects are removed using vegetation transmissivity collected in winter (Pulliainen, 2006).

GlobSnow SWE has been validated for several northern sites, and was found to have a root mean squared error (RMSE) of $33 \mathrm{~mm}$ (Luojus et al., 2009). GlobSnow SWE has been found to outperform other SWE algorithms, especially over >100 mm snowpacks (Luojus et al., 2010; Takala et al., 2011; Hancock et al., 2013). Overall, GlobSnow SWE has been found to perform well at estimating values of SWE up to $150 \mathrm{~mm}$. Thicker snowpacks act as a source of emission rather than a scattering medium, which leads to SWE being underestimated (Takala et al., 2011). Over Canadian tundra regions, this threshold has been observed at $130 \mathrm{~mm}$ (Derksen et al., 2010). It is also important to note that passive microwave retrievals of SWE are only reliable over $>15 \mathrm{~mm}$ snowpacks (Solberg et al., 2010), as thin snowpacks are difficult to detect. Similarly, although specific modifications are made to the GlobSnow SWE algorithm to enable accuracy over forested regions, the amount of SWE recorded over densely forested regions can be underestimated (Takala et al., 2011). GlobSnow estimates of SWE are therefore considered most reliable over the $15-150 \mathrm{~mm}$ range in forested regions without dense canopy cover, and over the $15-130 \mathrm{~mm}$ range over tundra regions.

\section{A2 NTSG air temperature (growing season)}

The central goal in the creation of the NTSG land surface variable data set was to gain accurate estimates of minimum and maximum air temperature (in Kelvin) at a height of $2 \mathrm{~m}$ using AMSR-E observations. The accuracy of NTSG air temperature estimates was improved by quantifying and removing the influence of vegetation, soil moisture and atmospheric water vapor on brightness temperature. Vegetation transmissivity and soil moisture variables were therefore extracted through this process (Jones and Kimball, 2010c). 
Minimum air temperature is calculated according to morning retrievals, and maximum air temperature is calculated according to late afternoon retrievals. Both estimates carefully account for the effects of vegetation, soil moisture, fractional cover of open water on land, and atmospheric water vapor. The complete details regarding calculations of air temperature can be found in Jones et al. (2010d). Air temperatures from meteorological stations were used for calibration (270 stations) and validation (273 stations) of resulting products, with these stations being assigned randomly. Comparisons indicated root mean squared error (RMSE) values of $3.5 \mathrm{~K}$ between AMSR-E derived temperature and meteorological data. Larger errors were observed in regions with sparse vegetation, higher elevations and higher fractional cover of open water on land. Non-desert regions had RMSE values between 1 and $3.5 \mathrm{~K}$, which shows better accuracy than previous approaches that had relied on carefully selected meteorological stations (Jones et al., 2010d). For the purpose of this project, daily air temperature was calculated as the daily average of maximum and minimum temperatures reported by Jones et al. (2010d).

\section{A3 NTSG soil moisture (growing season)}

The emissivity of soils depends largely on its dielectric properties. The real part of the dielectric constant increases as a function of soil moisture content. As a result, wetter soils have a diminished emissivity relative to drier soils (Njoku and Kong, 1977). Passive microwave observations are most sensitive to subsurface soil moisture at low $(\lesssim 3 \mathrm{GHz})$ frequencies, and at these low frequencies, the influences of vegetation and surface roughness is also limited (Njoku and Kong, 1977; Njoku and Chan, 2005).

The NTSG soil moisture product therefore relies primarily on the lowest AMSR-E frequency $(6.9 \mathrm{GHz})$ to generate estimates of surface $(\leq 2 \mathrm{~cm})$ soil moisture (Jones and Kimball, 2010a). Soil moisture is expressed as a dimension-free value ranging between $0-1$. Soil moisture was found to be correlated with precipitation at meteorological stations in the Northern Hemisphere $(0.2<r<0.8)$ (Jones and Kimball, 2010b).

\section{A4 NTSG vegetation transmissivity (growing season)}

Vegetation acts as an attenuating layer that diminishes the transmissivity of passive microwave radiation. The vegetation water content alters the dielectric properties of the landscape, such that there exists diminished emissivity over regions with greater vegetation water content (Jackson and O'Neill, 1990). Furthermore, the vegetation canopy layers influence scattering (Jones and Kimball, 2010a), generally resulting in increased scattering and diminished transmissivity over regions that have greater biomass, although the canopy structure (stem geometry, leaf orientation, angle distributions, spatial distribution, etc.) and type of vegetation also influence the surface roughness and scattering (Njoku and Chan, 2005; Jensen, 2007). The optical depth of vegetation can thus be defined according to the height of the attenuating layer $\left(z_{\text {top }}\right)$ and the extinction with height $\left(k(z)\right.$ in $\left.\mathrm{m}^{-1}\right)$ (Jones et al., 2010d):

$$
\tau=\int_{0}^{z_{\text {top }}} k(z) \mathrm{d} z .
$$

Over a vegetated region with a single species and relatively constant surface roughness, the attenuating influence of vegetation, or vegetation optical depth $(\tau)$, can be estimated as a linear function of canopy water content $\left(g\right.$ in $\left.\mathrm{kg} \mathrm{m}^{-2}\right)$ using a species-specific parameter $(b): \tau=b \times g$ (Jackson and O'Neill, 1990). A similar description is used by Jones et al. (2010d) to define the optical depth of northern hemispheric vegetation as a function of water content using a parameter $\alpha$ that expresses both the influences of roughness factors $(h)$ and look angle $(\theta)$, as well as frequency and angular impacts on canopy extinction $\left(b\right.$ in $\left.\mathrm{m}^{2} \mathrm{~kg}^{-1}\right)$ :

$\tau=\alpha g=b h g \sec (\theta)$.

Vegetation transmissivity to passive microwave radiation $(t)$ can be expressed as the logarithmically scaled counterpart of vegetation optical depth: $t=\exp (-\tau)$. Vegetation transmissivity is calculated iteratively from a combination of inverted analytical expressions using AMSR-E inputs, emissivity and ratios, as detailed in Jones et al. (2010d). Separate versions of the NTSG vegetation transmissivity product are available using inputs from the $6.9,10.7$ and $18.7 \mathrm{GHz}$ channels. There is a great deal of similarity between these observations, and so only the $10.7 \mathrm{GHz}$ channel is used in this analysis, just as in Njoku and Chan (2005).

Comparisons of this product with Moderate Resolution Imaging Spectroradiometer (MODIS)-derived leaf area index, normalized difference vegetation index (NDVI) and enhanced vegetation index yielded correlations of up to 0.9 (Jones et al., 2011). As the aforementioned MODIS products are typically used to estimate the vegetation health or quantity of aboveground biomass, it seems reasonable to assume that vegetation transmissivity likewise provides a relatively reliable estimate of the quantity of aboveground biomass.

\section{Appendix B}

\section{Limitations}

The AMSR-E derived products analyzed in this study are all established products that have been individually validated, as summarized in Appendix A. However, the retrieval of accurate estimates of land surface properties from satellite passive microwave observations remains an area of ongoing scientific progress, and uncertainties therefore exist in these estimates. Presently, GlobSnow passive microwave retrievals of 
Table A1. $R^{2}$ values from the linear regressions of SWE and air temperature (TA), SWE and volumetric soil moisture (MV), and of SWE and vegetation transmissivity at $10.7 \mathrm{GHz}$ (TC). Comparisons of SWE and growing-season observations were conducted by comparing mean annual 2003-2008 values (mean), and by examining associations between SWE at the end of the snow season with growing-season variables at the start of the growing season (spring), and between growing-season variables at the end of the growing season with SWE at the start of the snow season (autumn). $R^{2}$ values in single linear regression that correspond to a $p$ value $>0.01$ are marked with an asterisk.

\begin{tabular}{lllllllll}
\hline Var & Time & EVGRN & DECDS & MFRST & SHRUB & GRMTD & SRBTD & BARRN \\
\hline TA & Annual & 0.00 & 0.01 & $0.00^{*}$ & 0.02 & 0.11 & 0.04 & 0.20 \\
TA & Spring & 0.06 & 0.01 & 0.13 & 0.14 & 0.16 & 0.14 & 0.10 \\
TA & Autumn & 0.13 & 0.12 & 0.22 & 0.13 & 0.06 & 0.10 & 0.06 \\
\hline MV & Annual & 0.02 & 0.01 & 0.01 & 0.02 & 0.010 & 0.02 & $0.00^{*}$ \\
MV & Spring & 0.01 & $0.00^{*}$ & 0.00 & $0.00^{*}$ & $0.00^{*}$ & $0.00^{*}$ & 0.00 \\
MV & Autumn & 0.05 & 0.06 & 0.01 & 0.01 & 0.00 & 0.00 & 0.00 \\
\hline TC & Annual & 0.05 & 0.02 & 0.02 & 0.17 & 0.06 & 0.05 & 0.15 \\
TC & Spring & 0.20 & 0.11 & 0.23 & 0.28 & 0.20 & 0.19 & 0.18 \\
TC & Autumn & 0.16 & 0.28 & 0.22 & 0.16 & 0.02 & 0.06 & 0.03 \\
\hline TA, & Annual & 0.09 & 0.07 & 0.07 & 0.23 & 0.15 & 0.07 & 0.26 \\
MV, & Spring & 0.01 & 0.01 & 0.00 & 0.01 & 0.08 & 0.06 & 0.14 \\
TC) & Autumn & 0.13 & 0.11 & 0.08 & 0.12 & 0.04 & 0.02 & 0.08 \\
\hline
\end{tabular}

Table A2. $R^{2}$ values from the multiple linear regression of SWE vs. factor scores obtained from the principal component analysis (PCA) of TA, MV, and TC. The retained principal components (PC) are determined based on the proportion of explained variance, i.e. only PC accounting for $>10 \%$ of the total variance are included.

\begin{tabular}{llllllll}
\hline Time & EVGRN & DECDS & MFRST & SHRUB & GRMTD & SRBTD & BARRN \\
\hline Annual & 0.03 & 0.05 & 0.07 & 0.10 & 0.11 & 0.07 & 0.24 \\
Spring & 0.01 & 0.01 & 0.00 & 0.01 & 0.08 & 0.06 & 0.14 \\
Autumn & 0.13 & 0.11 & 0.08 & 0.12 & 0.04 & 0.02 & 0.08 \\
\hline
\end{tabular}

SWE are considered reliable over the $15-150 \mathrm{~mm}$ range in forested regions, and from 15 to $130 \mathrm{~mm}$ in tundra regions. SWE tends to be underestimated over thicker snowpacks. Analysis of the shape of the associations between SWE and growing-season variables therefore focuses primarily on values of SWE within these ranges. Furthermore, although the growing-season data sets have been found to perform reasonably well, there inevitably exist uncertainties in these data sets. The approach employed in this study takes into account the fact that these uncertainties exist, and therefore only compares relative values which are averaged over given time periods. For example, it is not assumed that estimates of SWE are highly accurate over very thick snowpacks, but that areas with greater mean reported values of SWE will, in fact, tend to have more snow accumulation than regions with smaller mean reported values of SWE.

The strength of conclusions drawn from the ACE approach is limited due to uncertainties in passive microwave estimates of land surface properties, and due to the inherently weak associations existing between snow and growing-season land surface properties as a result of numerous confounding factors (e.g. soil type, vegetation species composition, rainfall, permafrost). Furthermore, although field studies can reveal insight into the exact processes determining land surface properties, an assessment of similarities in coarse resolution $(25 \mathrm{~km})$ passive microwave-derived estimates of the land surface cannot reveal specific processes. All results presented are therefore discussed in relation to existing literature on in situ processes. Similarities are often found between the associations derived from ACE and observed in situ; in these cases, it is likely that the same mechanisms and processes observed at the field scale are dominating regional scale land surface conditions. However, it is beyond the scope of this approach to provide definitive conclusions on regional scale processes.

Finally, the relationships observed through the ACE analysis could be applied to generate estimates within the 2003 2008 time period. However, since these ecological linkages may be altered under changing climate regimes, the ACEderived empirical relationships cannot be used to predict future behaviour. Numerous studies have applied processbased models to predict the response of high-latitude regions to climate change, and this remains an important area of research. The ACE technique could, however, be applied to monitor the strength and directionality of ecological linkages in order to shed light on the response of northern 
Table B1. $R^{2}$ values of ACE transformed SWE and ACE transformed air temperature (TA), volumetric soil moisture (MV) and vegetation canopy transmissivity (TC). Linkages are indicated using observations collected over three non-overlapping time periods of the snow and growing seasons. Associations are therefore indicated between mean annual values of SWE and growing-season values, and between mean SWE 30 days prior to snowmelt and growing-season values 30 days following full snowmelt (Spring), and vice versa (Autumn). In the multivariate case, the $p$ values of all coefficients are statistically significant. All $p$ values corresponding to the pair-wise ACE transformations are $<10^{-5}$.

\begin{tabular}{lllllllll}
\hline Var & Time & EVGRN & DECDS & MFRST & SHRUB & GRMTD & SRBTD & BARRN \\
\hline TA & Annual & 0.08 & 0.04 & 0.06 & 0.04 & 0.33 & 0.20 & 0.38 \\
TA & Spring & 0.09 & 0.04 & 0.15 & 0.16 & 0.17 & 0.15 & 0.12 \\
TA & Autumn & 0.16 & 0.14 & 0.25 & 0.17 & 0.07 & 0.10 & 0.06 \\
\hline MV & Annual & 0.05 & 0.07 & 0.05 & 0.05 & 0.03 & 0.02 & 0.09 \\
MV & Spring & 0.04 & 0.02 & 0.03 & 0.17 & 0.08 & 0.06 & 0.05 \\
MV & Autumn & 0.06 & 0.12 & 0.10 & 0.08 & 0.09 & 0.06 & 0.07 \\
\hline TC & Annual & 0.10 & 0.03 & 0.12 & 0.26 & 0.25 & 0.19 & 0.29 \\
TC & Spring & 0.22 & 0.19 & 0.24 & 0.31 & 0.21 & 0.22 & 0.19 \\
TC & Autumn & 0.17 & 0.30 & 0.27 & 0.19 & 0.04 & 0.09 & 0.06 \\
\hline TA, & Annual & 0.20 & 0.33 & 0.13 & 0.34 & 0.37 & 0.29 & 0.47 \\
MV, & Spring & 0.07 & 0.14 & 0.02 & 0.06 & 0.17 & 0.11 & 0.19 \\
TC) & Autumn & 0.16 & 0.13 & 0.11 & 0.17 & 0.10 & 0.07 & 0.12 \\
\hline
\end{tabular}

environments to ongoing changes in snow and growingseason conditions. The role fulfilled by the analysis presented in this paper therefore fills a gap in literature, but is in no way a replacement for ongoing improvements in passive microwave-derived estimates of land surface properties, in situ investigations of processes, or predictions of how climate change may affect Arctic regions.

Acknowledgements. The authors would like to thank John Kimball and Lucas Jones (NTSG), and the GlobSnow FMI-led consortium for allowing public access to the AMSR-E Land Surface Parameter and GlobSnow Snow Water Equivalent data sets. Thank you also to the developers of $\mathrm{R}$ and the $\mathrm{R}$ acepack library, and to all anonymous reviewers. Funding for this research was provided by a Vanier Canada Graduate Scholarship (KL).

Edited by: P. Stoy

\section{References}

Adams, J., Bond, N., and Overland, J.: Regional variability of the Arctic heat budget in fall and winter, J. Climate, 13, 3500-3510, doi:10.1175/1520-0442(2000)013<3500:RVOTAH>2.0.CO;2, 2000.

Arft, A., Walker, M., Gurevitch, J., Alatalo, J., Bret-Harte, M., Dale, M., Diemer, M., Gugerli, F., Henry, G., Jones, M., Hollister, R., Jónsdóttir, I., Laine, K., Lévesque, E., Marion, G., Molau, U., Mølgaard, P., Nordenhäll, U., Raszhivin, V., Robinson, C., Starr, G., Stenström, A., Stenström, M., Totland, Ø., Turner, P., Walker, L., Webber, P., Welker, J., and Wookey, P.: Responses of tundra plants to experimental warming: meta-analysis of the international tundra experiment, Ecol. Monogr., 69, 4, 491-511, doi:10.2307/2657227, 1999.

Armstrong, R. and Brodzik, M.: Recent Northern Hemisphere snow extent: a comparison of data derived from visible and microwave satellite sensors, Geophys. Res. Lett., 28, 19, 36733676, doi:10.1029/2000GL012556, 2001.

Ashcroft, P. and Wentz, F.: AMSR-E/Aqua L2A Global Swath Spatially-Resampled Brightness Temperatures (Tb) V001, digital media, National Snow and Ice Data Center, Boulder, CO, 2003.

Ayres, E., Nkem, J., Wall, D., Adams, B., Barrett, J., Simmons, B., Virginia, R., and Fountain, A.: Experimentally increased snow accumulation alters soil moisture and animal community structure in a polar desert, Polar Biol., 33, 897-907, doi:10.1007/s00300-010-0766-3, 2010.

Bonan, G.: Ecological Climatology: Concepts and Applications, Cambridge Univ. Press, 2002.

Breiman, L. and Friedman, J.: Estimating optimal transformations for multiple regression and correlation, J. Am. Stat. Assoc., 80, 391, 580-598, doi:10.2307/2288477, 1985.

Burt, T. and Butcher, D.: Topographic controls of soil moisture distributions, Eur. J. Soil Sci., 36, 3, 469-486, doi:10.1111/j.13652389.1985.tb00351.x, 1985.

Callaghan, T., Johansson, M., Brown, R., Groisman, P., Labba, N., Radionov, V., Barry, R., Bulygina, O., Essery, R., Frolov, D., Golubev, V., Grenfell, T., Petrushina, M., Razuvaev, V., Robinson, D., Romanov, P., Shindell, D., Shmakin, A., Sokratov, S., Warren, S., and Yang, D.: The changing face of Arctic snow cover: a synthesis of observed and projected changes, AMBIO, 40, 1, 17-31, doi:10.1007/s13280-011-0212-y, 2011.

Church, J.: Snow surveying: its principles and possibilities, Geogr. Rev., 23, 4, 529-563, doi:10.2307/209242, 1933.

D'Agostino, R. and Stephens, M.: Goodness-of-fit Techniques, Vol. 68, CRC, 1986. 
Derksen, C., Toose, P., Rees, A., Wang, L., English, M., Walker, A., and Sturm, M.: Development of a tundra-specific snow water equivalent retrieval algorithm for satellite passive microwave data, Remote Sens. Environ., 114, 1699-1709, doi:10.1016/j.rse.2010.02.019, 2010.

Duguay, C., Green, J., Derksen, C., English, M., Rees, A., Sturm, M., and Walker, A.: Preliminary assessment of the impact of lakes on passive microwave snow retrieval algorithms in the Arctic, in: 62nd Eastern Snow Conference Proceedings, 2005.

Essery, R. and Pomeroy, J.: Vegetation and topographic control of wind-blown snow distributions in distributed and aggregated simulations for an arctic tundra basin, J. Hydrometeorol., 5, 735-744, doi:10.1175/15257541(2004)005<0735:VATCOW>2.0.CO;2, 2004.

Evans, B., Walker, D., Benson, C., Nordstrand, E., and Petersen, G.: Spatial interrelationships between terrain, snow distribution and vegetation patterns at an arctic foothills site in Alaska, Ecography, 12, 3, 270-278, doi:10.1111/j.1600-0587.1989.tb00846.x, 1989.

Fitzgibbon, J. and Dunne, T.: Characteristics of subarctic snowcover/Les caractéristiques de la couverture de neige presque arctique, Hydrolog. Sci. J., 24, 4, 465-476, doi:10.1080/02626667909491886, 1979.

Frank, I. and Lanteri, S.: ACE: a non-linear regression model, Chemometr. Intell. Lab., 3, 4, 301-313, doi:10.1016/01697439(88)80029-7, 1988

French, H. and Binley, A.: Snowmelt infiltration: monitoring temporal and spatial variability using time-lapse electrical resistivity, J. Hydrol., 297, 1-4, 174-186, doi:10.1016/j.jhydrol.2004.04.005, 2004.

Gatswirth, J., Gel, Y., and Miao, W.: The impact of Levene's test of equality of variances on statistical theory and practice, Stat. Sci., 24, 3, 343-360, doi:10.1214/09-STS301, 2009.

Gel, Y.: Comparative analysis of the local observation-based (LOB) method and the nonparametric regression-based method for gridded bias correction in mesoscale weather forecasting, Weather Forecast., 22, 6, 1243-1256, doi:10.1175/2007WAF2006046.1, 2007.

Gelfan, A., Pomeroy, J., and Kuchment, L.: Modeling forest cover influences on snow accumulation, sublimation, and melt, J. Hydrometeorol., 5, 5, 785-803, doi:10.1175/15257541(2004)005<0785:MFCIOS>2.0.CO;2, 2004.

Golding, D. and Swanson, R.: Snow distribution patterns in clearings and adjacent forest, Water Resour. Res., 22, 13, 1931-1940, doi:10.1029/WR022i013p01931, 1986.

Green, J., Kongoli, C., Prakash, A., Sturm, M., Duguay, C., and $\mathrm{Li}, \mathrm{S}$.: Quantifying the relationships between lake fraction, snow water equivalent and snow depth, and microwave brightness temperatures in an arctic tundra landscape, Remote Sens. Environ., 127, 329-340, doi:10.1016/j.rse.2012.09.008, 2012.

Grippa, M., Kergoat, L., Toan, T. L., Mognard, N., Delbart, N., L'Hermitte, J., and Vicente-Serrano, S.: The impact of snow depth and snowmelt on the vegetation variability over central Siberia, Geophys. Res. Lett., 32, 21, L21412, doi:10.1029/2005GL024286, 2005.

Hall, D., Kelly, R., Riggs, G., Chang, A., and Foster, J.: Assessment of the relative accuracy of hemispheric-scale snow-cover maps, Ann. Glaciol., 34, 1, 24-30, doi:10.3189/172756402781817770, 2002.
Hancock, S., Baxter, R. Evans, J. and Huntley, B.: Evaluating global snow water equivalent products for testing land surface models, Remote Sens. Environ., 128, 107-117, doi:10.1016/j.rse.2012.10.004, 2013.

Hardy, J., Groffman, P., Fitzhugh, R., Henry, K., Welman, A., Demers, J., Fahey, T., Driscoll, C., Tierney, G., and Nolan, S.: Snow depth manipulation and its influence on soil frost and water dynamics in a northern hardwood forest, Biogeochemistry, 56, 2, 151-174, doi:10.1023/A:1013036803050, 2001.

Hare, F.: The Arctic, Q. J. Roy. Meteor. Soc., 94, 402, 439-459, doi:10.1002/qj.49709440202, 1968.

Jackson, T. and O'Neill, P.: Attenuation of soil microwave emission by corn and soybeans at 1.4 and $5 \mathrm{GHz}$, IEEE T. Geosci. Remote, 28, 978-980, doi:10.1109/36.58989, 1990.

Janowicz, R., Gray, D., and Pomeroy, J.: Spatial variability of fall soil moisture and spring snow water equivalent within a mountainous sub-arctic watershed, in: Proceedings of the Eastern Snow Conference, Vol. 60, 127-139, 2003.

Jensen, J. R.: Remote Sensing of the Environment: An Earth Resource Perspective, 2nd edn., Pearson Prentice Hall, 2007.

Johnsson, H. and Lundin, L.-C.: Surface runoff and soil water percolation as affected by snow and soil frost, J. Hydrol., 122, 1-4, 141-159, doi:10.1016/0022-1694(91)90177-J, 1991.

Jones, L. and Kimball, J.: A global daily record of land surface parameter retrievals from AMSR-E Version 1.1, 2010a.

Jones, L. and Kimball, J.: Daily Global Land Surface Parameters Derived from AMSR-E, available at: http://nsidc.org/data/docs/daac/nsidc0451_amsre_derived_ land_params/pdfs/nsidc0451_amsre_land_parameters.pdf, 2010b.

Jones, L. A. and Kimball, J. S.: Daily Global Land Surface Parameters Derived from AMSR-E, digital media, 2010c.

Jones, L., Ferguson, C., Kimball, J., Zhang, K., Chan, S., McDonald, K., Njoku, E., and Wood, E.: Satellite microwave remote sensing of daily land surface air temperature minima and maxima from AMSR-E, IEEE J. Sel. Top. Appl., 3, 111-123, doi:10.1109/JSTARS.2010.2041530, 2010d.

Jones, M., Kimball, J., McDonald, K., and Jones, L.: Utilizing satellite passive microwave remote sensing for monitoring global land surface phenology, Remote Sens. Environ., 115, 4, 1102-1114, doi:10.1016/j.rse.2010.12.015, 2011.

Jones, L. and Kimball, J.: Daily Global Land Surface Parameters Derived from AMSR-E, digital media, National Snow and Ice Data Center, Boulder, Colorado, USA, 2012.

Jung, M., Henkel, K., Herold, M., and Churkina, G.: Exploiting synergies of global land cover products for carbon cycle modeling, Remote Sens. Environ., 101, 4, 534-553, doi:10.1016/j.rse.2006.01.020, 2006.

Kane, D., Hinzman, L., Benson, C., and Liston, G.: Snow hydrology of a headwater arctic basin 1. Physical measurements and process studies, Water Resour. Res., 27, 6, 1099-1109, doi:10.1029/91WR00262, 1991.

Kawanishi, T., Sezai, T., Ito, Y., Imaoka, K., Takeshima, T., Ishido, Y., Shibata, A., Miura, M., Inahata, H., and Spencer, R. The Advanced Microwave Scanning Radiometer for the Earth Observing System (AMSR-E), NASDA's contribution to the EOS for global energy and water cycle studies, IEEE T. Geosci Remote, 41, 184-194, doi:10.1109/TGRS.2002.808331, 2003. 
Kelly, R.: The AMSR-E snow depth algorithm: description and initial results, J. Remote Sens. Soc. Jpn., 29, 1, 307-317, 2009.

Chang, A., Foster, J., Hall, D.:Nimbus-7 SMMR derived global snow cover parameters, Ann. Glaciol., 9, 39-44, 1987.

Kim, Y., Kimball, J., McDonald, K., and Glassy, J.:Developing a global data record of daily landscape freeze/thaw status using satellite passive microwave remote sensing, IEEE T. Geosci. Remote, 49, 3, 949-960, doi:10.1109/TGRS.2010.2070515, 2011.

Knowles, K., Savoie, M., Armstrong, R., and Brodzik, M.: AMSRE/Aqua daily EASE grid brightness temperatures, available at: http://nsidc.org/data/nsidc-0301.html, NSIDC, 2010.

Levene, H.: Robust testes for equality of variances, in: Contributions to Probability and Statistics, Stanford University Press, 1960.

Liston, G. and Sturm, M.: Winter precipitation patterns in arctic Alaska determined from a blowing-snow model and snow-depth observations, J. Hydrometeorol., 3, 6, 646-659, doi:10.1175/1525-7541(2002)003<0646:WPPIAA>2.0.CO;2, 2002.

Loranty, M., Goetz, S., and Beck, P.: Tundra vegetation effects on pan-Arctic albedo. Enviro. Res. Lett., 6, 024014, doi:10.1088/1748-9326/6/2/024014, 2011.

Lundberg, A. and Halldin, S.: Snow interception evaporation. Review of measurement techniques, processes, and models, Theor. Appl. Climatol., 70, 1-4, 117-133, doi:10.1007/s007040170010, 2001.

Luojus, K., Pulliainen, J., and Derksen, C.: Snow Water Equivalent (SWE) Product Guide, Global Snow Monitoring for Climate Research, 0.9.1/01, 2009.

Luojus, K., Pulliainen, J., Takala, M., Lemmetyinen, J., Derksen, C., and Wang, L.: Snow Water Equivalent (SWE) Product Guide, Global Snow Monitoring for Climate Research, 1.0/01, 2010.

Luus, K., Kelly, R., Lin, J., Humphreys, E., Lafleur, P., and Oechel, W.: Modeling the influence of snow cover on low Arctic net ecosystem exchange, Environ. Res. Lett., 8, 035045, doi:10.1088/1748-9326/8/3/035045, 2013a.

Luus, K., Lin, J., Kelly, R., and Duguay, C.: Subnivean Arctic and sub-Arctic net ecosystem exchange (NEE) Towards representing snow season processes in models of NEE using cryospheric remote sensing, Prog. in Phys. Geogr., 37, 4, 484515, doi:10.1177/0309133313491130, 2013b.

MacDonald, M., Pomeroy, J., and Pietroniro, A.: Parameterizing redistribution and sublimation of blowing snow for hydrological models: tests in a mountainous subarctic catchment, Hydrol. Process., 23, 18, 2570-2583, doi:10.1002/hyp.7356, 2009.

Ménard, C., Essery, R., Pomeroy, J., Marsh, P., and Clark, D.: A shrub bending model to calculate the albedo of shrub-tundra, Hydrol. Process., doi:10.1002/hyp.9582, 2012.

Metcalfe, R. and Buttle, J.: A statistical model of spatially distributed snowmelt rates in a boreal forest basin, Hydrol. Process., 12, 1011, 1701-1722, doi:10.1002/(SICI)10991085(199808/09)12:10/11<1701::AID-HYP690>3.3.CO;2-4, 1998.

Morgner, E., Elberling, B., Strebel, D., Cooper, E.: The importance of winter in annual ecosystem respiration in the High Arctic: Effects of snow depth in two vegetation types, Polar Res., 29, 1, 58-74, doi:10.1111/j.1751-8369.2010.00151.x, 2010.
Naito, A. and Cairns, D.: Relationships between arctic shrub dynamics and topographically-derived hydrologic characteristics, Environ. Res. Lett., 6, 4, 045506, doi:10.1088/17489326/6/4/045506, 2011.

Njoku, E. and Chan, S.: Vegetation and surface roughness effects on AMSR-E land observations, Remote Sens. Environ., 100, 2, 190-199, doi:10.1016/j.rse.2005.10.017,2005.

Njoku, E. and Kong, J.: Theory for passive microwave remote sensing of near-surface soil moisture, J. Geophys. Res., 82, 20, 3108 3118, doi:10.1029/JB082i020p03108, 1977.

Nowinski, N., Taneva, L., Trumbore, S., and Welker, J.: Decomposition of old organic matter as a result of deeper active layers in a snow depth manipulation experiment, Oecologia, 163, 3, 785792, doi:10.1007/s00442-009-1556-x, 2010.

Olsson, P., Sturm, M., Racine, C., Romanovsky, V., and Liston, G.: Five stages of the Alaskan Arctic cold season with ecosystem implications, Arct. Antarct. Alp. Res., 35, 1, 7481, doi:10.1657/1523-0430(2003)035[0074:FSOTAA]2.0.CO;2, 2003.

Ostendorf, B. and Reynolds, J.: Relationships between a terrainbased hydrologic model and patch-scale vegetation patterns in an arctic tundra landscape, Land. Ecol., 8, 4, 229-237, doi:10.1007/BF00125130, 1993.

Overland, J., Adams, J., and Bond, N.: Regional variation of winter temperatures in the Arctic, J. Climate, 10, 5, 821-837, doi:10.1175/1520-0442(1997)010<0821:RVOWTI>2.0.CO;2, 1997.

Pomeroy, J., March, P., Jones, H., and Davies, T.: chap. Spatial distribution of snow chemical load at the tundra-taiga transition, in: Biogeochemistry of Seasonally Snow-Covered Catchments, IAHS, 191-206, 1995.

Pomeroy, J. and Dion, K.: Winter radiation extinction and reflection in a boreal pine canopy: Measurements and modelling, Hydrol. Process., 10, 1591-1608, doi:10.1002/(SICI)10991085(199612)10:12<1591::AID-HYP503>3.0.CO;2-8, 1996.

Pomeroy, J., Granger, R., Pietroniro, A., Elliott, J., Toth, B., and Hedstrom, N.: Hydrological Pathways in the Prince Albert Model Forest, Tech. rep., National Hydrology Research Institute Environment Canada, Saskatoon, Saskatchewan, 1997.

Pomeroy, J., Gray, D., Shook, K., Toth, B., Essery, R., Pietroniro, A., and Hedstrom, N.: An evaluation of snow accumulation and ablation processes for land surface modelling, Hydrol. Process., 12, 15, 2339-2367, doi:10.1002/(SICI)10991085(199812)12:15<2339::AID-HYP800>3.3.CO;2-C, 1999.

Pomeroy, J., Gray, D., Hedstrom, N., and Janowicz, J.: Prediction of seasonal snow accumulation in cold climate forests, Hydrol. Process., 16, 18, 3543-3558, doi:10.1002/hyp.1228, 2002.

Pomeroy, J., Bewley, D., Essery, R., Hedstrom, N., Link, T., Granger, R., Sicart, J., Ellis, C., and Janowicz, J.: Shrub tundra snowmelt, Hydrol. Process., 20, 4, 923-941, doi:10.1002/hyp.6124, 2006.

Prince, S. and Goward, S.: Global primary production: a remote sensing approach, J. Biogeogr., 22, 815-835, doi:10.2307/2845983, 1995.

Pulliainen, J.: Mapping of snow water equivalent and snow depth in boreal and sub-arctic zones by assimilating space-borne microwave radiometer data and ground-based observations, Remote Sens. Environ., 101, 2, 257-269, doi:10.1016/j.rse.2006.01.002, 2006. 
Pulliainen, J., Grandell, J., and Hallikainen, M.: HUT snow emission model and its applicability to snow water equivalent retrieval, IEEE T. Geosci. Remote, 37, 1378-1390, doi:10.1109/36.763302, 1999.

: R: A Language and Environment for Statistical Computing, Vienna, Austria, ISBN 3-900051-07-0, http://www.R-project.org/, 2013.

Rees, A., Derksen, C., English, M., Walker, A., and Duguay, C.: Uncertainty in snow mass retrievals from satellite passive microwave data in lake-rich high-latitude environments, Hydrol. Process., 20, 1019-1022, doi:10.1002/hyp.6076, 2006.

Rigor, I., Colony, R., and Martin, S.: Variations in surface air temperature in the Arctic, J. Climate, 13, 896-914, doi:10.1175/1520-0442(2000)013<0896:VISATO>2.0.CO;2, 2000.

Ritchie, J. and Hare, F.: Late-quaternary vegetation and climate near the arctic treeline of northwestern North America, Quaternary Res., 1, 331-342, doi:10.1016/0033-5894(71)90069-X, 1971.

Rouse, W.: Soil microclimate of tundra and forest, Water Resour. Res., 20, 1, 67-73, doi:10.1029/WR020i001p00067, 1984.

Serreze, M. and Barry, R.: The Arctic Climate System, Cambridge Univ. Press, 2005.

Shinoda, M.: Climate memory of snow mass as soil moisture over central Eurasia, J. Geophys. Res., 106, 33393-33403, doi:10.1029/2001JD000525, 2001.

Sitch, S., McGuire, A. D., Kimball, J., Gedney, N., Gamon, J., Engstrom, R., Wolf, A., Zhuang, Q., Clein, J., and McDonald, K. C.: Assessing the carbon balance of circumpolar Arctic tundra using remote sensing and process modeling, Ecol. Appl., 17, 1, 213-234, doi:10.1890/10510761(2007)017[0213:ATCBOC]2.0.CO;2, 2007.

Smith, C., Burn, C., Tarnocai, C. and Sproule, B.: Air and soil temperature relations along an ecological transect through the permafrost zones of northwestern Canada, Proceedings, Seventh International Conference on Permafrost, 23-26, 1998.

Solberg, R., Amlien, J., Koren, H., Wangensteen, B., Luojus, K., Pulliainen, J., Takala, M., Lemmetyinen, J., Nagler, T., Rott, H., Muller, F., Derksen, C., Metsamaki, S., and Bottcher, K.: Global snow monitoring for climate research: Design justication file. European Space Agency contract report, ESRIN contract 21703/08/I-EC, Deliverable 1.7, 2010.

Spector, P., Friedman, J., Tibshirani, R. and Lumley, T.: acepack: ace() and avas() for selecting regression transformations, available at http://CRAN.R-project.org/package=acepack, 2013.

Staple, W., Lehane, J., and Wenhardt, A.: Conservation of soil moisture from fall and winter precipitation, Can. J. Soil Sci., 40, 1, 80-88, doi:10.4141/cjss60-010, 1960.

Stiles, W. and Ulaby, F.: The active and passive microwave response to snow parameters 1 . Wetness, J. Geophys. Res., 85, C2, 10371044, doi:10.1029/JC085iC02p01037, 1980.

Sturm, M., Holmgren, J., and Liston, G.: A seasonal snow cover classification system for local to global applications, J. Climate, 8, 5, 1261-1283, doi:10.1175/15200442(1995)008<1261:ASSCCS>2.0.CO;2, 1995.

Sturm, M., Holmgren, J., McFadden, J., Liston, G., Chapin III, F., and Racine, C.: Snow-shrub interactions in Arctic Tundra: A hypothesis with climatic implications, J. Climate, 14, 3, 336-344, doi:10.1175/1520-0442(2001)014<0336:SSIIAT>2.0.CO;2, 2001a.
Sturm, M., Pielke Sr, R., and Chapin III, F.: Interactions of shrubs and snow in arctic tundra: measurements and models, in: SoilVegetation-Atmosphere Transfer Schemes and Large-Scale Hydrological Models, Proceedings of an International Symposium (Symposium S5) held during the Sixth Scientific Assembly of the International Association of Hydrological Sciences (IAHS) at Maastricht, The Netherlands, from 18 to 27 July 2001, vol. 270, 317, International Assn of Hydrological Sciences, $2001 \mathrm{~b}$.

Sturm, M., Douglas, T., Racine, C., and Liston, G.: Changing snow and shrub conditions affect albedo with global implications, J. Geophys. Res., 110, G01004, doi:10.1029/2005JG000013, 2005.

Sullivan, P., Welker, J., Arens, S., and Sveinbjörnsson, B..: Continuous estimates of $\mathrm{CO}_{2}$ efflux from arctic and boreal soils during the snow-covered season in Alaska, J. Geophys. Res.,113, G04009, doi:10.1029/2008JG000715, 2008.

Suzuki, K., Kubota, J., Ohata, T., and Vuglinsky, V.: Influence of snow ablation and frozen ground on spring runoff generation in the Mogot Experimental Watershed, southern mountainous taiga of eastern Siberia, Nord. Hydrol., 37, 21-29, doi:10.2166/nh.2005.027, 2006.

Takala, O., Pulliainen, J., Metsämäki, S., and Koskinen, J.: Detection of snowmelt using spaceborne microwave radiometer data in Eurasia From 1979 to 2007, IEEE T. Geosci. Remote, 47, 9, 2996-3007, doi:10.1109/TGRS.2009.2018442, 2009.

Takala, M., Luojus, K., Pulliainen, J., Derksen, C., Lemmetyinen, J., Kärnä, J., Koskinen, J., and Bojkov, B.: Estimating Northern Hemisphere snow water equivalent for climate research through assimilation of space-borne radiometer data and groundbased measurements, Remote Sens. Environ., 115, 21, 35173529, doi:10.1016/j.rse.2011.08.014, 2011.

Tranquillini, W.: The physiology of plants at high altitudes, Ann. Rev. Plant Physio., 15, 1, 345-362, doi:10.1146/annurev.pp.15.060164.002021, 1964.

Wahren, C., Walker, M., and Bret-Harte, M.: Vegetation responses in Alaskan arctic tundra after 8 years of a summer warming and winter snow manipulation experiment, Glob. Change Biol., 11, 4, 537-552, doi:10.1111/j.1365-2486.2005.00927.x, 2005.

Walker, D., Billings, W., and De Molenaar, J.: Snow-vegetation interactions in tundra environments, in: Snow Ecology: an Interdisciplinary Examination of Snow-Covered Ecosystems, 266-324, 2001.

Walker, D., Raynolds, M., Daniëls, F., Einarsson, E., Elvebakk, A., Gould, W., Katenin, A., Kholod, S., Markon, C., Melnikov, E., Moskalenko, N., Talbot, S., Yurtsev, B., Bliss, L., Edlund, S., Zoltai, S., Wilhelm, M., Bay, C., Gudjónsson, G., Ananjeva, G., Drozdov, D., Konchenko, L., Korostelev, Y., Ponomareva, O., Matveyeva, N., Safranova, I., Shelkunova, R., Polezhaev, A., Johansen, B., Maier, H., Murray, D., Fleming, M., Trahan, N., Charron, T., Lauritzen, S., and Vairin, B.: The Circumpolar Arctic vegetation map, J. Veg. Sci., 16, 3, 267-282, doi:10.1658/11009233(2005)016[0267:TCAVM]2.0.CO;2, 2005.

Walker, M., Walker, D., Welker, J., Arft, A., Bardsley, T., Brooks, P., Fahnestock, J., Jones, M., Losleben, M., Parsons, A., Seastedt, T., and Turner, P.: Long-term experimental manipulation of winter snow regime and summer temperature in arctic and alpine tundra, Hydrol. Process., 13, 14-15, 2315-2330, 
doi:10.1002/(SICI)1099-1085(199910)13:14/15<2315::AIDHYP888>3.0.CO;2-A, 1999.

Wang, D. and Murphy, M.: Estimating optimal transformations for multiple regression using the ACE algorithm,J. Data Sci., 2, 329346, 2004.

Wardle, P.: Engelmann spruce (Picea engelmannii Engel.) at its upper limits on the Front Range, Colorado, Ecology, 49, 3, 483495, doi:10.2307/1934115, 1968.

Williams, M. and Ratsetter, E.: Vegetation characteristics and primary productivity along an Arctic transect: implications for scaling-up, J. Ecol., 87, 5, 885-898, doi:10.1046/j.13652745.1999.00404.x, 1999.
Willis, W., Carlson, C., Alessi, J., and Haas, H.: Depth of freezing and spring run-off as related to fall soil-moisture level, Can. J. Soil Sci., 41, 1, 115-123, doi:10.4141/cjss61-014, 1961.

Zhang, T., and Armstrong, R.:Soil freeze/thaw cycles over snow-free land detected by passive microwave remote sensing,Geophys. Res. Lett., 28, 5, 763-766, doi:10.1029/2000GL011952, 2001.

Zhao, L. and Gray, D.: Estimating snowmelt infiltration into frozen soils, Hydrol. Process., 13, 12-13, 1827-1842, doi:10.1002/(SICI)1099-1085(199909)13:12/13<1827::AIDHYP896>3.0.CO;2-D, 1999. 